University of Wollongong

Research Online

Faculty of Engineering and Information

Faculty of Engineering and Information

Sciences - Papers: Part B

Sciences

2019

Insight into the improved cycling stability of sphere-nanorod-like micronanostructured high voltage spinel cathode for lithium-ion batteries

Haiping Liu

University of Wollongong, Harbin Institute of Technology

Gemeng Liang

University of Wollongong, gl906@uowmail.edu.au

Chao Gao

Harbin Institute of Technology

Sifu Bi

Harbin Institute of Technology

Qiang Chen

Harbin Institute of Technology

See next page for additional authors

Follow this and additional works at: https://ro.uow.edu.au/eispapers1

Part of the Engineering Commons, and the Science and Technology Studies Commons

Research Online is the open access institutional repository for the University of Wollongong. For further information contact the UOW Library: research-pubs@uow.edu.au 


\title{
Insight into the improved cycling stability of sphere-nanorod-like micro- nanostructured high voltage spinel cathode for lithium-ion batteries
}

\begin{abstract}
Currently, developing cathode material with high energy density and good cycling performance is one of

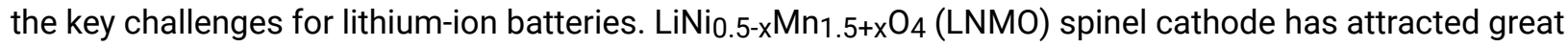
attention as the most promising cathode candidate due to its extraordinarily high operating voltage, but its inferior long-term cycling stability has limited its further development. In this work, we successfully designed LNMOs with specific facets and different morphologies, among which the hybrid spherenanorod-like micro-nanostructured LNMO possesses excellent cycling performance, with capacity of over $107.8 \mathrm{mAh} \mathrm{g}^{-1}$ after 1000 cycles at $10 \mathrm{C}$ and superior rate capability up to $10 \mathrm{C}$. Its superior rate capability is found to originate from the large $\mathrm{Li}-\mathrm{O}$ bond length by Rietveld refinement, which contributes to decreased charge transfer resistance and ease of $\mathrm{Li}$ insertion/extraction at tetrahedral sites. On the other hand, the excellent cycling stability comes from its having the least structural deformation from mechanistic reactions, which involve the longest solid-solution reaction, the highest spinel structural tolerance/stability up to $\Delta=\sim 0.69 \mathrm{Li}$, and a highly reversible two-phase reaction during charge and discharge in the hybrid LNMO, as revealed by the in operando synchrotron X-ray powder diffraction results. Moreover, the hybrid LNMO exhibits surface planes (210) with the highest Mn defect formation energy, prohibiting $\mathrm{Mn}^{3+}$ disproportionation and further stabilizing its cycling stability. This work not only demonstrates the importance of crystallographic and morphological controls on the high-voltage spinel performance, but also opens a window for battery engineers and researchers to develop battery technology for high-power applications.

Disciplines

Engineering | Science and Technology Studies

\section{Publication Details}

Liu, H., Liang, G., Gao, C., Bi, S., Chen, Q., Xie, Y., Fan, S., Cao, L., Pang, W. \& Guo, Z. (2019). Insight into the improved cycling stability of sphere-nanorod-like micro-nanostructured high voltage spinel cathode for lithium-ion batteries. Nano Energy, 66 104100-1-104100-9.

\section{Authors}

Haiping Liu, Gemeng Liang, Chao Gao, Sifu Bi, Qiang Chen, Ying Xie, Shanshan Fan, Lixin Cao, Wei Kong Pang, and Zaiping Guo
\end{abstract}


1 Insight into the improved cycling stability of sphere-nanorod-like micro-

2 nanostructured high voltage spinel cathode for lithium-ion batteries

3 Haiping Liu ${ }^{\mathrm{a}, \mathrm{b}, 1, *}$, Gemeng Liang ${ }^{\mathrm{b}, 1}$, Chao $\mathrm{Gao}^{\mathrm{a}}$, Sifu Bi ${ }^{\mathrm{c}}$, Qiang Chen ${ }^{\mathrm{a}}$, Ying Xie ${ }^{\mathrm{d}, *}$, 4 Shanshan Fan ${ }^{\mathrm{a}}$, Lixin $\mathrm{Cao}^{\mathrm{a}}$, Wei Kong Pang ${ }^{\mathrm{b}, *}$, Zaiping Guo ${ }^{\mathrm{b}, *}$

5 a School of Marine Science and Technology, Harbin Institute of Technology, Weihai 6 264209, PR China.

7 b School of Mechanical, Materials, Mechatronic and Biomedical Engineering, Institute 8 for Superconducting \& Electronic Materials, University of Wollongong, NSW 2522, 9 Australia.

10 c School of Materials Science and Engineering, Harbin Institute of Technology, Weihai 11 264209, PR China.

12 d Key Laboratory of Functional Inorganic Material Chemistry, Ministry of Education, 13 School of Chemistry and Materials Science, Heilongjiang University, Harbin, 150080, 14 PR China.

Keywords: lithium-ion batteries; high-voltage spinel; hybrid morphology; high rate 17 performance; superior cycling stability

Abstract

20 Currently, developing cathode material with high energy density and good cycling 21 performance is one of the key challenges for lithium-ion batteries. $\mathrm{LiNi}_{0.5-x} \mathrm{Mn}_{1.5+x} \mathrm{O}_{4}$ (LNMO) spinel cathode has attracted great attention as the most promising cathode candidate due to its extraordinarily high operating voltage, but its inferior long-term

24 cycling stability has limited its further development. In this work, we successfully 25 designed LNMOs with specific facets and different morphologies, among which the

\footnotetext{
* Corresponding author at:

E-mail address: hpliuhit@126.com (H.-P. Liu), xieying@hlju.edu.cn (X. Ying), wkpang@uow.edu.au (W. K.

Pang), zguo@uow.edu.au (Z.Guo)

${ }^{1}$ These authors contributed equally to this work.
} 
1 hybrid sphere-nanorod-like micro-nanostructured LNMO possesses excellent cycling

2 performance, with capacity of over $107.8 \mathrm{mAh} \mathrm{g}^{-1}$ after 1000 cycles at $10 \mathrm{C}$ and superior

3 rate capability up to $10 \mathrm{C}$. Its superior rate capability is found to originate from the large

4 Li-O bond length by Rietveld refinement, which contributes to decreased charge

5 transfer resistance and ease of $\mathrm{Li}$ insertion/extraction at tetrahedral sites. On the other

6 hand, the excellent cycling stability comes from its having the least structural

7 deformation from mechanistic reactions, which involve the longest solid-solution

8 reaction, the highest spinel structural tolerance/stability up to $\Delta=\sim 0.69 \mathrm{Li}$, and a highly

9 reversible two-phase reaction during charge and discharge in the hybrid LNMO, as

10 revealed by the in operando synchrotron X-ray powder diffraction results. Moreover,

11 the hybrid LNMO exhibits surface planes (210) with the highest Mn defect formation

12 energy, prohibiting $\mathrm{Mn}^{3+}$ disproportionation and further stabilizing its cycling stability.

13 This work not only demonstrates the importance of crystallographic and morphological

14 controls on the high-voltage spinel performance, but also opens a window for battery

15 engineers and researchers to develop battery technology for high-power applications.

\section{Introduction}

Recently, Li-ion batteries have been proposed as a potential energy source for the

18 electric vehicle and hybrid electric vehicle because of its high energy density and good

19 superior cyclability [1-4]. As one of the most promising high-voltage cathode materials,

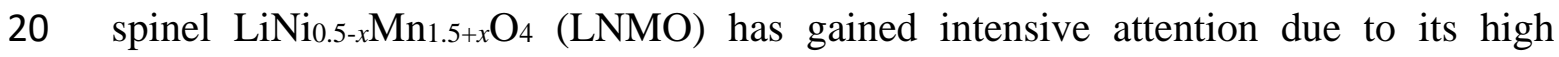
21 working voltage of $4.7 \mathrm{~V}\left(v s . \mathrm{Li} / \mathrm{Li}^{+}\right)$, its high energy density of $650 \mathrm{Wh} \mathrm{kg}^{-1}$, and its 22 rapid transportation of lithium ions via three-dimensional (3D) diffusion tunnels in the 23 spinel structure [5-9]. Nevertheless, its inferior cycle capability, especially its severe 24 capacity decay when working at high temperature or high voltage because of disastrous 25 side reactions, such as $\mathrm{Mn}^{3+}$ disproportionation and dissolution, etc., is the main 26 obstacle for the commercialization of LNMO.

27 Generally speaking, the structural stability and the surface states of LNMO are the two most important factors for excellent electrochemical performance [5, 10, 11]. On the 
1 one hand, spinel LNMO can be classified into two groups, namely ordered spinel with

2 a simple cubic structure and space group of $P 4332$, and disordered spinel with a face-

3 centered cubic structure with $F d-3 m$ symmetries[12, 13]. Ni and Mn ions occupy the

4 octahedral sites, connecting with $\mathrm{O}$ atoms to form a 3D octahedral network in both

5 spinels. Note that $\mathrm{Ni}$ and Mn occupy the $4 b$ and $12 d$ sites, respectively, in the $P 4_{3} 32$

6 structure and Ni shares the $16 d$ sites with $\mathrm{Mn}$ in disordered structure (Fig. S1 in the

7 Supporting Information). The structural differences result in different mechanistic

8 behavior of the ordered and disordered phases. Apparently, the working plateaus for the

$9 \mathrm{Ni}^{2+} / \mathrm{Ni}^{3+}$ and $\mathrm{Ni}^{3+} / \mathrm{Ni}^{4+}$ redox couples are separated in the disordered phase, but are not 10 distinguishable in the ordered phase. Mechanistically, the ordered phase undergoes 11 multiple two-phase reactions during $\mathrm{Ni}^{2+} / \mathrm{Ni}^{3+} / \mathrm{Ni}^{4+}$ redox reactions, whereas the 12 disordered spinel exhibits a solid-solution reaction and a two-phase reaction during the corresponding $\mathrm{Ni}^{2+} / \mathrm{Ni}^{3+}$ and $\mathrm{Ni}^{3+} / \mathrm{Ni}^{4+}$ redox couples, respectively. In addition, in the ordered phase, $\mathrm{Mn}$ only exists in the form of $\mathrm{Mn}^{4+}$, while in the disordered phase, $\mathrm{Mn}$ has $3^{+}$and $4^{+}$valences, giving rise to the $4 \mathrm{~V}$ plateau of the $\mathrm{Mn}^{3+} / \mathrm{Mn}^{4+}$ redox reactions [12, 14]. Electrochemically, the disordered spinel shows better electrochemical performance due to its higher stability. The degree of $\mathrm{Ni} / \mathrm{Mn}$ disorder and the concentration of $\mathrm{Mn}^{3+}$ ions also play important roles in mandating the electrochemical performance of the disordered phase [11, 15]. Aside from the intrinsic mechanistic reactions, the $\mathrm{Mn}^{3+}$ dissolution is the key impediment to the cycling performance of 21 Mn-based electrodes, including LNMOs.

22 On the other hand, the crystallographic facets of LNMO particles could result in 23 different electrochemical properties, through mitigating the $\mathrm{Mn}^{3+}$ dissolution and 24 promoting the Li diffusion during cycling [10, 16, 17]. For example, some researchers 25 suggested that the densest (111) planes have the lowest surface energy and the lowest 26 Mn dissolution, which could contribute to a stable solid electrolyte interphase (SEI) and 27 a resultant excellent cycle life [10]. On the other hand, the dissolution of $\mathrm{Mn}^{2+}$ into the 28 electrolyte is proposed to be more likely to occur at the (110) planes [16]. There is still 
1 debate about this issue, however, and other researchers reported that the (100) planes

2 are more stable and favorable to long-term cycling stability [17].

3 To prepare LNMO materials with good cycling performance, the synthesis method is

4 one of the key factors and needs to be optimized. Until now, the solid-state method [18,

5 19], co-precipitation method [20], hydrothermal method [21], sol-gel method [22],

6 molten salt method [23], etc. have been used to prepare the LNMO materials. Recent

7 studies also show that different synthesis methods can result in different microstructures

8 and different surface states of the LNMOs, which have a non-negligible influence on

9 the electrochemical performance, via shortening the Li diffusion paths for the lithium

10 ions [24-26] and limiting the $\mathrm{Mn}^{3+}$ dissolution [27]. Surface coating_[28-30] cation or

11 anion doping [31-33], and morphology control [34, 35] have also been applied to

12 improve the cycling performance of LNMO to a certain extent. Despite these earlier

13 studies, the enhancement mechanisms that act on the cycling properties of LNMO due

14 to this surface morphology and microstructure are not yet clear and need to be further

15 investigated, which is crucial, extendable, and desirable for the design and development

16 of novel cathode materials.

17 In our previous work, we found that the LNMO/graphene composites with nanorod morphology featured better electrochemical performances, but the long-term cycling stability of the nanorod LNMO material is still far from satisfactory [36]. As the structure and the surface states are very important for the cycling performance of

21 LNMO, in this work, we designed LNMOs with different microstructures and different morphologies via the one-pot hydrothermal-calcination method. We further enhanced 23 the disordered LNMOs with morphological control and design of the surface 24 orientation using a one-pot hydrothermal method and subsequent solid-state method. 25 The spherical, nanorod, and hybrid sphere-nanorod LNMOs exhibit excellent, but 26 slightly different, electrochemical performances. Comprehensive and comparative 27 investigations have been performed to illustrate the origins of the structural and electrochemical properties of these three microstructured LNMO materials by means 
1 of electrochemical evaluation, electron imaging, in operando synchrotron-based X-ray

2 diffraction (XRD), and ab initio calculations.

\section{Experimental}

\subsection{Material preparation}

Three LNMO materials with different morphologies were synthesized separately by the hydrothermal-calcination method, and the synthetic process is graphically illustrated in Fig. S2. For the nanorod LNMO, the MnOOH nanorods precursor was first prepared through a template method, with $\mathrm{KMnO}_{4}$ (97\%, Sigma Aldrich) as one of the raw materials and polyethylene glycol (PEG-400, Sigma Aldrich) as the template. The detailed preparation process is described in our previous studies [36].

For the spherical LNMO, the spherical $\mathrm{Ni} 0.25 \mathrm{Mn}_{0.75} \mathrm{CO}_{3}$ precursor was firstly prepared by a co-precipitation method, using $\mathrm{NiSO}_{4}$ (99.99\%, Sigma Aldrich) and $\mathrm{MnSO}_{4}$ (99.99\%, Sigma Aldrich) as the raw materials, and $\mathrm{NH}_{4} \mathrm{HCO}_{3}$ (99.5\%, Sigma Aldrich) as the precipitator. The obtained precursor was then heated at $160{ }^{\circ} \mathrm{C}$ for 3 hours in a Teflon-lined hydrothermal reactor. After that, the obtained materials were filtered with deionized water and then washed with ethanol (99.8\%, Sigma Aldrich), followed by drying in an oven at $90{ }^{\circ} \mathrm{C}$ for 12 hours to obtain the hollow sphere-like precursors. Then, the obtained precursors were dispersed in deionized water with the appropriate amount of $\mathrm{LiOH} \cdot \mathrm{H}_{2} \mathrm{O}$ (99.99\%, Sigma Aldrich) (5\% excess,), stirred for 3 hours, and dried in an oven at $80{ }^{\circ} \mathrm{C}$ for 24 hours. Then, the mixture was moved to a furnace and air-annealed at $800{ }^{\circ} \mathrm{C}$ for $10 \mathrm{~h}$ to obtain the sphere-like LNMO material.

The hybrid sphere-nanorod micro-nanostructured LNMO was also synthesized by a one-pot hydrothermal-calcination method. In this synthesis process, the spherical $\mathrm{Ni}_{0.25} \mathrm{Mn}_{0.75} \mathrm{CO}_{3}$ precursor and the $\mathrm{MnOOH}$ nanorods precursor were firstly prepared by a hydrothermal process, corresponding to part 1 in Fig. S2. Then, the spherical $\mathrm{Ni}_{0.25} \mathrm{Mn}_{0.75} \mathrm{CO}_{3}$ precursor and the $\mathrm{MnOOH}$ precursor were mixed in a 1:1 ratio (by weight), transferred into Teflon-lined hydrothermal reactor, and heated at $160{ }^{\circ} \mathrm{C}$ for 3 hours. After that, the obtained materials were filtered and washed with deionized water 
1 and ethanol for many times. After mixing with a Li source, the mixture was moved to

2 a furnace and annealed at $800{ }^{\circ} \mathrm{C}$ for $10 \mathrm{~h}$ to obtain the sphere-nanorod-like micro-

3 nanostructured LNMO material, corresponding to part 2 in Fig. S2.

\subsection{Material characterization}

The morphology of the prepared samples was characterized by field-emission scanning electron microscopy (FESEM, NERLIN Compact, Zeiss, Germany), equipped with a Quanta-450 SEM instrument, and transmission electron microscopy (TEM, JEOL2100). In addition to X-ray diffraction (XRD), neutron powder diffraction (NPD) was carried out to characterize the structure and composition of the active materials on the highresolution neutron powder diffractometer ECHIDNA [37] at the Open Pool Australian Light Water (OPAL) research reactor at the Australian Nuclear Science and Technology Organization (ANSTO). The NPD data were collected over the 2-theta range of 4-164 with a step-size of $0.125^{\circ}$. The wavelength of the neutron beam was determined to be 1.62157(5) Å using $\mathrm{LaB}_{6}$ standard reference material 660b. Rietveld refinement was carried out using GSAS-II software [38], where the refining parameters include background coefficients, zero shift, peak shape parameters, lattice parameter, oxygen positional parameter, site occupancy factors, and isotropic atomic displacement parameters. The three LNMOs were also characterized using Raman spectroscopy (Renishaw in Via, Britain using $532 \mathrm{~nm}$ excited laser) for structural analysis in the spectral range from 200 to $800 \mathrm{~cm}^{-1}$.

The electrochemical properties of the obtained LNMO materials were studied using CR2025 coin-type cells. The CR2025 cells were assembled in a glove box filled with argon (Universal 2440/750, Mikrouna), and the content of oxygen and moisture was less than $0.1 \mathrm{ppm}$. The cathode electrode was fabricated by mingling the obtained LNMO material, polyvinylidene difluoride (PVDF) binder, and conductive carbon black in the mass ratio of 8: 1: 1 with an adequate amount of $\mathrm{N}$-methyl-2-pyrrolidone (NMP), and then coating the mixture on an aluminum current collector to form the electrode; the cathode material loading was $2-3 \mathrm{mg} \mathrm{cm}^{-2}$. The electrode was dried at 
$190{ }^{\circ} \mathrm{C}$ for 3 hours in an air oven and then diverted to a vacuum oven and dried at $90{ }^{\circ} \mathrm{C}$

2 for 8 hours to evaporate the excessive solvent, then pressed into circles of diameter 15

3 mm. Lithium foil and polypropylene membrane (Celgard ${ }^{\circledR}$ 2400) were used as the

4 counter electrode and separator, respectively. $1 \mathrm{~mol} \mathrm{~L}^{-1} \mathrm{LiPF}_{6}$ dissolved in a 1: 1 mixture

5 of dimethyl carbonate (DMC) and ethylene carbonate (EC) was prepared and used as

6 the electrolyte in the batteries. Galvanostatic charge/discharge performance was tested

7 on a Land 2000T auto-cycler (China) at several current densities in the voltage range

8 of $3.5-4.9 \mathrm{~V}$ vs. $\mathrm{Li} / \mathrm{Li}^{+}$at room temperature. The electrochemical impedance

9 spectroscopy (EIS) tests were performed using a CHI electrochemical workstation (CHI $660 \mathrm{E}$ ) in the frequency range from 0.01 to $10^{5} \mathrm{~Hz}$.

11 The in operando synchrotron-based XRD experiment was carried out in Australian 12 Synchrotron, Australia. The preparation method for the customized coin cell can be found elsewhere [39, 40].The wavelength of the synchrotron beam was 0.688800(1) $\AA$, determined by using the $\mathrm{LaB}_{6}$ standard reference material 660b. The diffraction pattern was continuously recorded with the acquisition time of $180 \mathrm{~s}$ per pattern using a MYTHEN microstrip detector. The time gap between each pattern was around 828 seconds during discharging and charging processes. The coin cell for the in operando experiment was tested at $0.1 \mathrm{C}\left(1 \mathrm{C}=147 \mathrm{~mA} \mathrm{~g}^{-1}\right)$ in the voltage range from 3.5 to 4.9 V.

20 The density functional theory (DFT) calculations were performed by using the Vienna 21 Ab initio Simulation Package (VASP) [41-44]. For all calculations, the Perdew-BurkeErnzerhof (PBE) functional [45] and the projector augmented-wave (PAW) technique [46] were applied. Geometry optimization was converged until the energy change was less than $10^{-5} \mathrm{eV}$ and the force less than $-0.03 \mathrm{eV} / \AA$. Furthermore, the energy cut-off was set to $400 \mathrm{eV}$, and the sampling over the Brillouin zone was treated by a $2 \times 2 \times 1$ grid for the surfaces. To avoid the pseudo interactions of periodic images along the zaxis, a vacuum slab with a thickness of $15 \AA$ was introduced. 
2 Fig. 1a and 1b present the hollow spherical material and the nanorod material,

\section{Results and discussion}

respectively. It can be seen that the diameter of the spherical particles is about 1-2 $\mu \mathrm{m}$ and the wall thickness of the hollow spheres is about 200-300 nm, whereas the length of the LNMO nanorods is about 1 2 $\mu \mathrm{m}$, with diameters of around 300-500 nm. Fig. 1c shows the LNMO with hybrid sphere-nanorod-like micro-nanostructured morphology. Compared with Figure. 1a and 1b, the spheres and the nanorod-like particles in the sphere-nanorod-like materials are similar in size and shape. It is noteworthy that the nanorod-like and spherical hollow particles are connected to each other in the hybrid sample, reducing the barrier energy and easing the lithium migration, which makes its electrochemical performance significantly different from the physical mixture of the nanorod and spherical samples.

The microstructure and surface morphology of the three LNMO samples were further characterized by TEM and high-resolution TEM (HRTEM), as shown in Fig. 1d, 1e and 1f. In Fig. 1d, the structure of the sphere-like sample was examined. It showed lattice spacing of $0.29 \mathrm{~nm}$, corresponding to the (220) lattice planes. Fig. 1e displays an overview of the structure of the nanocrystals of the nanorod-like LNMO material, and the internal HRTEM image shows clear lattice fringes with the lattice spacing of 0.47 $\mathrm{nm}$, corresponding to the interplanar spacing for the (111) planes. As for the hybrid LNMO material, an overview of the structure and an HRTEM image of the lattice fringe patterns of the selected sphere-like and nanorod-like particles are displayed in Fig. 1f. The lattice spacing of the circled sphere particle is $0.29 \mathrm{~nm}$, indicating that the sphere particles grow along the [220] direction, whereas the nanorod-like particles show the lattice spacings of $0.37 \mathrm{~nm}$ and $0.47 \mathrm{~nm}$, indexed to the (210) and (111) planes respectively. Accordingly, the three LNMO samples with different surface morphologies show different preferred orientations, and a new (210) plane was detected in the sphere-nanorod sample, which may have different effects on the electrochemical properties of LNMO materials. 
1 The XRD patterns of the three LNMOs are similar, as shown in Fig. S3. In order to

2 further identify the structural and crystallographic details of the three samples, neutron

3 powder diffraction (NPD) was adopted because of the better elemental contrast between

$4 \mathrm{Ni}$ and $\mathrm{Mn}$, and the higher sensitivity towards $\mathrm{Li}$ and $\mathrm{O}$ of the neutrons [47]. This

5 superiority derives from the unique coherent scattering lengths of different elements.

6 For instance, in the LNMO system, $\mathrm{Li}, \mathrm{Ni}, \mathrm{Mn}$, and $\mathrm{O}$ have the values of $-1.9,10.3$, -

$7 \quad 3.7$ and $-5.8 \mathrm{fm}\left(1 \mathrm{fm}=10^{-13} \mathrm{~cm}\right)$, respectively [48]. The Rietveld refinement results are

8 shown in Fig. 1g-1i and Tables S1-S3, respectively. All three samples were refined to

9 be cubic with the $F d-3 m$ group symmetry. Among them, the nanorod sample features

10 the largest lattice parameter of 8.1801(7) $\AA$ and cell volume of 547.3(1) $\AA^{3}$, followed

11 by hybrid sphere-nanorod sample and the sphere sample. Interestingly, it is found that 12 the ratio of $\mathrm{Ni}$ ions to $\mathrm{Mn}$ ions in the unit cells of the three samples are all refined to be 13 around 1:4, which may lead to an increased concentration of $\mathrm{Mn}^{3+}$ as a result of less $14 \mathrm{Ni}^{2+}$ content. Considering that $\mathrm{Mn}^{3+}$ has a larger ionic radius $(0.645 \AA)$ than $\mathrm{Mn}^{4+}(0.53$ $15 \AA$ ), the increased $\mathrm{Mn}^{3+}$ content probably accounts for the larger lattice parameter than that in our previous report [49]. It should be noted that the degree of $\mathrm{Ni} / \mathrm{Mn}$ disorder and the concentration of $\mathrm{Mn}^{3+}$ ions are critical for mandating the electrochemical performance of the disordered phase [11, 15]. In addition, the Ni: Mn ratio (1:4) makes it different from the typical $\mathrm{LiNi}_{0.5} \mathrm{Mn}_{1.5} \mathrm{O}_{4}$ (1:3) material. Our refinement profiles also show that LNMO in the three samples exists in both ordered and disordered phases, where the disordered content accounts for the majority. Meanwhile, minor impurities are refined to include the rock-salt $\mathrm{Li}_{x} \mathrm{Ni}_{2-x} \mathrm{O}_{2}$ phase (space group Fm-3m, ICSD\#71422) and spinel $\mathrm{Li}_{x} \mathrm{Mn}_{2} \mathrm{O}_{4}$ phase (space group Fd-3m, ICSD\#50415), which were probably introduced during the sintering process. We note that the sample with hybrid 25 morphology contains the least impurities compared to the other two samples, with 26 LNMO accounting for 91.6(2) wt\% of the composite. Although the impurity phases 27 inevitably decrease the capacity of the electrode, their influence on the battery electrochemical performance will be ignored in the following discussion due to the 
1 minor nature of their content. Last but not least, the lengths of the Li-O bonds and

$2 \mathrm{Mn}(\mathrm{Ni})-\mathrm{O}$ bonds were also investigated. It is shown that the hybrid LNMO has the

3 longest Li-O bond length of 1.9552(4) Å, implying easy Li insertion into/extraction

4 from the tetrahedral sites during the cycling process, and the longest $\mathrm{Mn}-\mathrm{O}$ bond is in

5 the nanorod LNMO, also implying instability of the octahedra in the structure.

6 Furthermore, Raman spectroscopy was also used to further analyze the LNMO

7 materials, and the results are shown in Fig. S4. Similarly, as per the results in the

8 literature [13, 50], the two main Raman bands peaking at about 487-489 and 623-624

$9 \mathrm{~cm}^{-1}$ can be assigned to the $\mathrm{Ni}^{2+}-\mathrm{O}$ stretching mode and the $\mathrm{Mn}-\mathrm{O}$ stretching vibration

10 of $\mathrm{MnO}_{6}$ groups, respectively, consistent with the features of the $F d$-3m space group of

11 LNMO.

12 The electrochemical performances of these three LNMO materials at room temperature 13 were evaluated. The first discharge curves of these samples at $1 \mathrm{C}$ in the voltage range 14 between 3.5 and $4.9 \mathrm{~V}$ (vs. $\mathrm{Li} / \mathrm{Li}^{+}$) are presented in Fig. 2a. All the curves at $1 \mathrm{C}$ show 15 similar features in their discharge behavior with two long plateaus at around $4.7 \mathrm{~V}$ and 16 a short plateau at or near $4.0 \mathrm{~V}$. The plateaus at $\sim 4.7 \mathrm{~V}$ are attributed to the $17 \mathrm{Ni}^{4+} / \mathrm{Ni}^{3+} / \mathrm{Ni}^{2+}$ redox couple, while the plateau at $\sim 4.0 \mathrm{~V}$ is ascribed to the $\mathrm{Mn}^{3+} / \mathrm{Mn}^{4+}$ 18 redox couple, which confirms the conclusion drawn in the Rietveld refinements that $19 \mathrm{Mn}^{3+}$ exists in the LNMO [13]. At $1 \mathrm{C}$, the total discharge capacities of the sphere 20 LNMO, nanorod LNMO, and hybrid LNMO are 117.1, 96.9, and $124.2 \mathrm{mAh} \mathrm{g}^{-1}$, 21 respectively. In order to clarify the importance of the one-pot synthesis for hybrid 22 LNMO, a mechanical mixture of sphere-like and nanorod-like LNMO (in a mass ratio 23 of 1:1) was also prepared and evaluated for comparison purposes. The three 24 microstructured LNMOs and the mechanical mixture of LNMOs were tested for 100 25 cycles at $1 \mathrm{C}$ (Fig. 2b). After the 100 cycles at $1 \mathrm{C}$, the hybrid LNMO delivered the 26 highest discharge capacity (122 $\left.\mathrm{mAh} \mathrm{g}^{-1}\right)$, significantly higher than those of the sphere27 like, nanorod, and mixed LNMOs (115.4, 97.7, $106.2 \mathrm{mAh} \mathrm{g}$, respectively). 28 Furthermore, Fig. 2c displays the rate capabilities of these three samples at various 
1 current densities between $0.1 \mathrm{C}$ and $10 \mathrm{C}$, each sustained for 8 cycles. With the current

2 density increased from $0.1 \mathrm{C}$ to $10 \mathrm{C}$ sequentially, the capacities of the hybrid and 3 sphere LNMOs were much higher than that of the nanorod sample, especially at the 4 high rates of $5 \mathrm{C}$ and $10 \mathrm{C}$. For example, the hybrid LNMO material delivered a capacity 5 of $108 \mathrm{mAh} \mathrm{g}^{-1}$, while the sphere LNMO delivered $105 \mathrm{mAh} \mathrm{g}^{-1}$ and the nanorod 6 LNMO only exhibited $72 \mathrm{mAh} \mathrm{g}^{-1}$ at $10 \mathrm{C}$. More importantly, when the current density 7 was returned to $0.1 \mathrm{C}$, the capacities for all these three materials were higher than the 8 initial values, which may be related to wetting and electrochemical activation processes.

9 It is believed that this is the reason for the increasing trend in the capacities at the initial 10 stage for these three samples. In addition, as shown in Fig. S5, the hybrid LNMO also 11 shows larger capacities at $1 \mathrm{C}$ and $5 \mathrm{C}$ than samples in previous reports. Fig. 2d shows 12 the EIS plots of the three samples, and the inset is the equivalent circuit, with the corresponding fitting parameters shown in Table S4. All the EIS plots contain a semicircle in a high-frequency region corresponding to the charge transfer resistance $15\left(R_{\mathrm{ct}}\right)$, and a straight line in the low-frequency region related to the Warburg impedance $\left(Z_{\mathrm{w}}\right)$, which is associated with the solid phase diffusion of Li-ion in the electrodes $[51$, 52]. In addition, in the equivalent circuit, $C_{\mathrm{d} 2}$ is placed to represent the double-layer 18 capacitance, while $C_{\mathrm{d} 1}$ and $R_{\mathrm{I}}$ are the insertion capacitance and resistance at the applied potential. We found that the hybrid LNMO had lower charge transfer resistance $\left(R_{\mathrm{ct}}\right)$ than the other samples, which is beneficial to the kinetic behavior during charge/discharge processes, and thus favorable to enhance the electronic conductivity. It also had the longest Li-O bond lengths, as determined in NPD, explaining its having the best rate performance obtained in the cycle tests. At $10 \mathrm{C}$, the first discharge capacities of the hybrid sphere-nanorod-like LNMO, the single sphere LNMO, the 25 mechanical mixture, and the single nanorod LNMO were 95.9, 86.6, 81.7, and 58.8 $26 \mathrm{mAh} \mathrm{g}^{-1}$, respectively. After 1000 cycles at $10 \mathrm{C}$, however, the sphere-nanorod 27 microstructured LNMO material could still deliver a capacity of $107.4 \mathrm{mAh} \mathrm{g}^{-1}$, demonstrating the excellent cycling performance of the hybrid LNMO, even at high C 
1 rates (Fig. 2e). To conclude, at $1 \mathrm{C}$ discharge, all these three samples showed good

2 cycling performance, whereas at $10 \mathrm{C}$, the hybrid LNMO material displayed the best

3 cycling stability with the highest discharge capacity. There was no obvious capacity

4 decay at high current density even after the 1000 cycles. It should be noted that the

5 hybrid LNMO not only shows a higher capacity, but also better cycling performance

6 than the mixed LNMO, demonstrating the necessity of the one-pot synthesis and the

7 bridging features between the nanorod-like and spherical hollow particles, as observed

8 in the hybrid LNMO.

9 In short, the LNMO materials with various microstructures exhibited excellent but 10 different electrochemical performances, especially at high current density. In order to 11 further reveal the underlying mechanism of enhanced electrochemical performance in 12 the hybrid morphology LNMO, in operando synchrotron-based XRD was used to 13 illustrate the differences in the structural changes and phase evolution of the three samples during the charging and discharging processes (shown in Fig. 3). As mentioned above, ordered and disordered LNMOs show different electrochemical behavior during the lithiation and delithiation processes [53]. It was reported that the typical ordered $\mathrm{LiNi}_{0.5} \mathrm{Mn}_{1.5} \mathrm{O}_{4}$ undergoes two cubic/cubic two-phase reactions during the charging process, from $\mathrm{LiNi}_{0.5} \mathrm{Mn}_{1.5} \mathrm{O}_{4}(a=8.17 \AA)$ to $\mathrm{Li}_{0.5} \mathrm{Ni}_{0.5} \mathrm{Mn}_{1.5} \mathrm{O}_{4}(a=8.09 \AA)$ and finally to $\mathrm{Ni}_{0.5} \mathrm{Mnn}_{1.5} \mathrm{O}_{4}(a=8.00 \AA)$ [54]. On the other hand, the typical disordered $\mathrm{LiNi}_{0.5} \mathrm{Mn}_{1.5} \mathrm{O}_{4}$ phase undergoes the combination of a solid-solution reaction at the $21 \mathrm{Ni}^{2+} / \mathrm{Ni}^{3+}$ redox couple at the voltage of around $4.6 \mathrm{~V}$ (vs. $\mathrm{Li}^{2} / \mathrm{Li}^{+}$, from $\mathrm{LiNi} 0.5 \mathrm{Mn}_{1.5} \mathrm{O}_{4}$ to $\mathrm{Li} 0.5 \mathrm{Ni}_{0.5} \mathrm{Mn}_{1.5} \mathrm{O}_{4}$ ) and a two-phase reaction during the $\mathrm{Ni}^{3+} / \mathrm{Ni}^{4+}$ redox couple stage at approximately $4.7 \mathrm{~V}$ (vs. $\mathrm{Li}_{/} / \mathrm{Li}^{+}$, from $\mathrm{Li} 0.5 \mathrm{Ni} 0.5 \mathrm{Mn}_{1.5} \mathrm{O}_{4}$ to $\mathrm{Ni} 0.25 \mathrm{Mn} 0.75 \mathrm{O}_{2}$ ) [49]. Generally speaking, the two-phase reactions usually involve phase segregation and grain boundary movement, inevitably leading to the problems of active material pulverization and electrical contact loss from the current collectors [47]. It should be

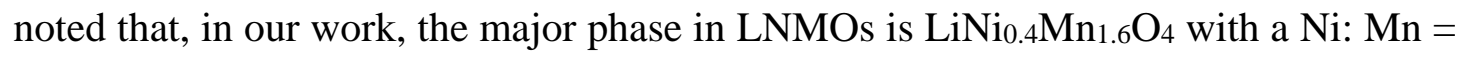
1:4 ratio, considering that $20 \%$ of $\mathrm{Ni}^{2+}$ is replaced by $\mathrm{Mn}^{3+}$. The phase evolutions of 
1 these LNMOs are expected to be similar, but also come with slight differences. The

2 solid-solution reaction (one-phase reaction) is generally preferable due to its having

3 fewer structural changes and higher transformation reversibility.

4 In order to show the peak shift and new peak occurrence in more detail, a selected

5 region of 2-theta has been exhibited, and the 111 reflections of LNMO phase were

6 chosen to illustrate the structural response of disordered LNMO. Meanwhile, the peak

7 position evolution of the (511) reflection is also shown in Fig. S6. From Fig. 3, it can

8 be obtained that all LNMOs suffer a solid-solution reaction and a subsequent two-phase

9 reaction, corresponding to the redox couples of $\mathrm{Mn}^{3+} / \mathrm{Mn}^{4+}, \mathrm{Ni}^{2+} / \mathrm{Ni}^{3+}$, and $\mathrm{Ni}^{3+} / \mathrm{Ni}^{4+}$,

10 respectively, in the charging process, similar to those of typical $\mathrm{LiNi}_{0.5} \mathrm{Mn}_{1.5} \mathrm{O}_{4}$ reported

11 in the previous literature [49]. In the case of the charge behavior, we can see that the 12 solid-solution reaction contributes $68.9 \%(\sim 0.69 \mathrm{Li}), 63.6 \%$, and $56.8 \%$ to the 13 capacities of the hybrid, sphere-like, and nanorod-like LNMOs, demonstrating that the 14 hybrid LNMO exhibits the best structural stability and tolerance, so that it allows more 15 Li to be extracted. This observation explains why the hybrid LNMO has the best cycling 16 performance at 1 and $10 \mathrm{C}$ rates. Although the two-phase reaction at the high charge 17 stage constitutes of less than $50 \%$ of the capacity and is not avoidable, its reasonable 18 reversibility on discharge does not harm the cycling performance of the LNMOs to any 19 significant degree. When extra attention is paid to the discharge behavior, during the 20 solid-solution stage, the peak location of the (111) reflection continuously shifts to 21 lower angles, corresponding to a lattice deformation with an increasing lattice 22 parameter and cell volume upon the insertion of Li. The existence of a rapid structure 23 breakdown, which is highlighted by the red boxes in the contour plots and inevitably 24 leads to structural instability, in both the sphere-like and the nanorod-like LNMOs, may 25 be the culprit in the poorer cycling performance. In comparison, the hybrid LNMO 26 features a smooth structural deformation during discharge, and its peak returns to 27 almost its initial position at the end of discharging, which indicates the excellent structural stability of the hybrid LNMO sample. 
1 For high-voltage and Mn-based cathodes, the dissolution of $\mathrm{Mn}^{3+}$ ions, under the

2 effects of electrolyte decomposition, HF attack, high current, and high voltage is 3 another major concern for the cycle performance [55, 56]. From Fig. 1, it can be

4 obtained that the three LNMO samples with different surface morphologies show

5 different preferred orientations, which may result in different degrees of side reactions

6 in the LNMO materials. Therefore, to evaluate the influence of the morphology and

7 resultant surface facets on the issue of $\mathrm{Mn}^{3+}$ dissolution, density functional theory (DFT)

8 calculations were performed using the Vienna $a b$ initio Simulation Package (VASP)

9 [41-44]. It is worth mentioning that the model of LNMO was designed as

$10 \mathrm{LiNi} 0.5 \mathrm{Mn}_{1.5} \mathrm{O}_{4}$ in order to simplify the calculation issues.

11 According to above experimental observations in HRTEM (Fig. 1), several 12 representative surfaces were constructed, and VASP was employed to perform DFT 13 calculations on the formation energies of Mn defects on different surface facets (as 14 depicted in Fig. S7), according to the following equation,

$$
\mathrm{LiNi}_{0.5} \mathrm{Mn}_{1.5} \mathrm{O}_{4}(\text { surf. }) \rightarrow \mathrm{LiNi}_{0.5} \mathrm{Mn}_{1.5-\chi} \mathrm{O}_{4}(\text { surf. })+x M n
$$

The calculation results listed in Table S5 clearly show that the Mn species on (100), (110), (210), and their equivalent (i.e. (010) or (101) ones) surfaces are stable, although the dissolution of Mn ions from (111) and equivalent surfaces is easy. As a result, it can be expected that LNMO materials with exposed (111) and equivalent facets will be unstable and suffer from capacity reduction during repeated charging/discharging cycles, while the LNMO with exposed (100), (110), (210), and equivalent facets will exhibit excellent stabilities. The corresponding equivalent surfaces of these three LNMO samples and the formation energies of $\mathrm{Mn}$ ion dissolution from the corresponding surfaces are summarized in Fig. 4. Although a very recent investigation suggested that the dissolution energy of Mn follows the order of $(111)>(100)>(110)$ [57], our calculations have clearly shown that the stability of Mn ions on the surface is strongly correlated with the Mn-O coordination. For the (100) clean surface, Mn is 5fold coordinated with oxygen, whereas the coordination number of Mn ions on the 
1 outermost layer of the (111) clean surface is reduced to 3, which leads to a lower

2 dissolution energy and is responsible for their lower stability on the surface. Therefore,

3 as shown in the TEM images (Fig. 1), the hybrid LNMO with dominant (111) and (210)

4 facets should exhibit less Mn dissolution compared with the sphere-like (with (220)

5 facets) and nanorod-like (with (111) facets) LNMOs.

6 In short, the hybrid LNMO exhibits the best electrochemical performance for the 7 following reasons:

8 1) The longest Li-O bond of 1.9552(4) $\AA$ exists in the hybrid LNMO, as 9 confirmed by Rietveld refinement, which is coupled with the lowest charge transfer transfer resistance into the hybrid LNMO, leading to superior rate capability.

\section{Conclusion}

In this paper, LNMO materials with a $\mathrm{Ni} / \mathrm{Mn}$ ratio of 1:4 and various morphologies have been successfully prepared by a one-pot hydrothermal-calcination process. Notably, the hybrid sphere-nanorod-like micro-nanostructured LNMO material reveals outstanding high rate performance and excellent cycling stability. Through chemical and morphological controls, we introduced a large Li-O bond length and low charge Meanwhile, the in operando synchrotron XRD results show that the hybrid LNMO 
1 delivered up to $69 \%$ charging capacity through a solid-solution reaction and

2 experienced smooth structural deformation during discharge, which accounts for its

3 excellent structural stability during the cycling process. Moreover, theoretical

4 calculations also indicate that the existence of (210) planes in the hybrid LNMO could

5 help to alleviate the side reactions leading to Mn dissolution, further ensuring its cycling

6 stability. This work not only demonstrates the successful preparation of a high-

7 performance, high-voltage spinel through chemical and morphological modifications,

8 but also provides insight into the origins of its electrochemical behavior and its

9 enhancement mechanisms.

11 Acknowledgments

12 H.-P. Liu and G. Liang contributed equally to this work. This research is supported by 13 the China Scholarship Fund, the Natural Science Foundation of Shandong Province 14 (ZR2018MEM017), the National Natural Science Foundation of China (NSFC) (Grant 15 No. 51301052), the Natural Science Foundation of Heilongjiang Province (E2016056), 16 and the Young Scholar Project of the Long Jiang Scholars Program (Q201818). The 17 authors are grateful for support from the Australian Research Council (ARC) through 18 Future Fellowship projects (FT150100109 and FT160100251). The authors also greatly 19 appreciate support from the HIT \& Yun Shan Group Program for Research and 20 Development on Graphite. In addition, the authors would also like to thank the 21 Australian Institute of Nuclear Science and Engineering (AINSE) for their financial 22 help in the form of a Post Graduate Research Award (PGRA) to carry out this work. 23 The authors are very grateful to the operational support of Australian Centre for Neutron 24 Scattering (ACNS) staffs, especially Dr. Vanessa Peterson and Dr. Christophe Didier, 25 on the collection of high-resolution neutron powder diffraction data and the technical 26 support of Australian Synchrotron staffs, especially Dr. Helen Brand and Dr. Qinfen Gu, 27 on the in operando synchrotron X-ray powder diffraction measurements. 


\section{References:}

2 [1] X. Han, X. Gui, T.-F. Yi, Y. Li, C. Yue, Current Opinion in Solid State and Mater. 3 Sci. 22 (2018) 109-126.

4 [2] W. Xiao, J. Wang, L. Fan, J. Zhang, X. Li, Energy Storage Mater. 19 (2019) 3795400.

6 [3] T.-F. Yi, Y.-R. Zhu, W. Tao, S. Luo, Y. Xie, X.-F. Li, J. Power Sources 399 (2018) 7 26-41.

8 [4] H. Maleki Kheimeh Sari, X. Li, Adv. Energy Mater. (2019) 1901597.

9 [5] J. Xiao, X. Chen, P.V. Sushko, M.L. Sushko, L. Kovarik, J. Feng, Z. Deng, J. Zheng, 10 G.L. Graff, Z. Nie, Adv. Mater. 24 (2012) 2109-2116.

11 [6] N.P. Pieczonka, Z. Liu, P. Lu, K.L. Olson, J. Moote, B.R. Powell, J.-H. Kim, J. Phys. 12 Chem. C 117 (2013) 15947-15957.

13 [7] J. Ma, P. Hu, G. Cui, L. Chen, Chem. Mater. 28 (2016) 3578-3606.

14 [8] J. Feng, Z. Huang, C. Guo, N.A. Chernova, S. Upreti, M.S. Whittingham, ACS Appl. 15 Mater. Interfaces 5 (2013) 10227-10232.

16 [9] Y.-J. Gu, Y. Li, Y. Fu, Q.-F. Zang, H.-Q. Liu, J.-X. Ding, Y.-M. Wang, H.-F. Wang, 17 J. Ni, Electrochim. Acta 176 (2015) 1029-1035.

18 [10] K.R. Chemelewski, D.W. Shin, W. Li, A. Manthiram, J. Mater. Chem. A 1 (2013) 19 3347-3354.

20 [11] J.-H. Kim, S.-T. Myung, C. Yoon, S. Kang, Y.-K. Sun, Chem. Mater. 16 (2004) 21 906-914.

22 [12] N.D. Rosedhi, N.H. Idris, M.M. Rahman, M.M. Din, J. Wang, Electrochim. Acta 23206 (2016) 374-380.

24 [13] L. Wang, H. Li, X. Huang, E. Baudrin, Solid State Ionics 193 (2011) 32-38.

25 [14] N. Amdouni, K. Zaghib, F. Gendron, A. Mauger, C. Julien, Ionics 12 (2006) 11726126.

27 [15] M.R. Jo, Y.I. Kim, Y. Kim, J.S. Chae, K.C. Roh, W.S. Yoon, Y.M. Kang, 28 ChemSusChem 7 (2014) 2248-2254.

29 [16] H. Liu, J. Wang, X. Zhang, D. Zhou, X. Qi, B. Qiu, J. Fang, R. Kloepsch, G. 30 Schumacher, Z. Liu, ACS Appl. Mater. Interfaces 8 (2016) 4661-4675.

31 [17] B. Chen, L. Ben, Y. Chen, H. Yu, H. Zhang, W. Zhao, X. Huang, Chem. Mater. 30 32 (2018) 2174-2182.

33 [18] Y. He, J. Zhang, Q. Li, Y. Hao, J. Yang, L. Zhang, C. Wang, J. Alloys Compd. 715 34 (2017) 304-310.

35 [19] J. Zheng, J. Xiao, X. Yu, L. Kovarik, M. Gu, F. Omenya, X. Chen, X.-Q. Yang, J. 
1 Liu, G.L. Graff, Phys. Chem. Chem. Phys. 14 (2012) 13515-13521.

2 [20] T.-F. Yi, X.-G. Hu, J. Power Sources 167 (2007) 185-191.

3 [21] A. Cao, A. Manthiram, Phys. Chem. Chem. Phys. 14 (2012) 6724-6728.

4 [22] S. Wang, P. Li, L. Shao, K. Wu, X. Lin, M. Shui, N. Long, D. Wang, J. Shu, Ceram.

5 Int. 41 (2015) 1347-1353.

6 [23] J.-H. Kim, S.-T. Myung, Y.-K. Sun, Electrochim. Acta 49 (2004) 219-227.

7 [24] T.-F. Yi, J. Mei, Y.-R. Zhu, J. Power Sources 316 (2016) 85-105.

8 [25] Y. Yang, C. Xie, R. Ruffo, H. Peng, D.K. Kim, Y. Cui, Nano Lett. 9 (2009) 410994114.

10 [26] L. Zhou, D. Zhao, X. Lou, Angew. Chem., Int. Ed. 51 (2012) 239-241.

11 [27] Z. Lu, Y. Liu, X. Lu, H. Wang, G. Yang, Y. Chao, W. Li, F. Yin, J. Power Sources 12360 (2017) 409-418.

13 [28] T.-F. Yi, Y.-M. Li, X.-Y. Li, J.-J. Pan, Q. Zhang, Y.-R. Zhu, Sci. Bull. 62 (2017) 14 1004-1010.

15 [29] J. Liu, Y. Cheng, Q. Fan, L. Zhang, L. Liu, X. Ke, N. Wang, Z. Shi, Z. Guo, Mater. 16 Lett. 214 (2018) 68-71.

17 [30] W. Liu, X. Li, D. Xiong, Y. Hao, J. Li, H. Kou, B. Yan, D. Li, S. Lu, A. Koo, K. 18 Adair, X. Sun, Nano Energy 44 (2018) 111-120.

19 [31] J. Yoon, M. Jeong, I.T. Bae, K.-W. Nam, W.-S. Yoon, J. Power Sources 368 (2017) 20 1-10.

21 [32] J. Hao, H. Liu, Y. Ji, S. Bi, Sci. China Mater. 60 (2017) 315-323.

22 [33] Y. Luo, H. Li, T. Lu, Y. Zhang, S.S. Mao, Z. Liu, W. Wen, J. Xie, L. Yan, 23 Electrochim. Acta 238 (2017) 237-245.

24 [34] Y. Liu, M. Zhang, Y. Xia, B. Qiu, Z. Liu, X. Li, J. Power Sources 256 (2014) 662571.

26 [35] A.K. Haridas, C.S. Sharma, T.N. Rao, Electrochim. Acta 212 (2016) 500-509.

27 [36] Q. Chen, H. Liu, J. Hao, S. Bi, C. Gao, L. Chen, Ionics 25 (2019) 99-109.

28 [37] K.-D. Liss, B. Hunter, M. Hagen, T. Noakes, S. Kennedy, J. Phys. B 385 (2006) $29 \quad 1010-1012$.

30 [38] B.H. Toby, R.B. Von Dreele, J. Appl. Cryst. 46 (2013) 544-549.

31 [39] W.K. Pang, V.K. Peterson, N. Sharma, C. Zhang, Z. Guo, J. Phys. Chem. C 118 32 (2014) 3976-3983.

33 [40] Q. Gu, J.A. Kimpton, H.E. Brand, Z. Wang, S. Chou, Adv. Energy Mater. 7 (2017) 341602831. 
1 [41] G. Kresse, J. Hafner, Phys. Rev. B 47 (1993) 558.

2 [42] G. Kresse, J. Hafner, Phys. Rev. B 49 (1994) 14251.

3 [43] G. Kresse, J. Furthmüller, Phys. Rev. B 54 (1996) 11169.

4 [44] G. Kresse, J. Furthmüller, Comput. Mater. Sci 6 (1996) 15-50.

5 [45] J.P. Perdew, K. Burke, M. Ernzerhof, Phys. Rev. Lett. 77 (1996) 3865.

$6 \quad$ [46] P.E. Blöchl, Phys. Rev. B 50 (1994) 17953.

7 [47] V.K. Peterson, J.E. Auckett, W.-K. Pang, IUCrJ 4 (2017) 540-554.

8 [48] G. Liang, A.S. Pillai, V.K. Peterson, K.-Y. Ko, C.-M. Chang, C.-Z. Lu, C.-E. Liu,

9 S.-C. Liao, J.-M. Chen, Z. Guo, W.K. Pang, Front. Energy Res. 6 (2018).

10 [49] W.K. Pang, N. Sharma, V.K. Peterson, J.-J. Shiu, S.-h. Wu, J. Power Sources 246 11 (2014) 464-472.

12 [50] J. Song, D.W. Shin, Y. Lu, C.D. Amos, A. Manthiram, J.B. Goodenough, Chem. 13 Mater. 24 (2012) 3101-3109.

14 [51] P. Gao, C. Zhang, G. Wen, J. Power Sources 294 (2015) 67-74.

15 [52] T.-F. Yi, P.-P. Peng, Z. Fang, Y.-R. Zhu, Y. Xie, S. Luo, Composites Part B: 16 Engineering 175 (2019) 107067.

17 [53] W.K. Pang, H.-F. Lin, V.K. Peterson, C.-Z. Lu, C.-E. Liu, S.-C. Liao, J.-M. Chen, 18 J. Phys. Chem. C 121 (2017) 3680-3689.

19 [54] K. Ariyoshi, Y. Iwakoshi, N. Nakayama, T. Ohzuku, J. Electrochem. Soc. 151 20 (2004) A296-A303.

21 [55] X. Ke, Z. Zhao, J. Liu, Z. Shi, Y. Li, L. Zhang, H. Zhang, Y. Chen, Z. Guo, Q. Wu, 22 Appl. Energy 194 (2017) 540-548.

23 [56] A. Bhaskar, S. Krueger, V. Siozios, J. Li, S. Nowak, M. Winter, Adv. Energy Mater. 245 (2015) 1401156.

25 [57] W. Sun, Y. Li, K. Xie, S. Luo, G. Bai, X. Tan, C. Zheng, Nano Energy 54 (2018) $26 \quad 175-183$. 

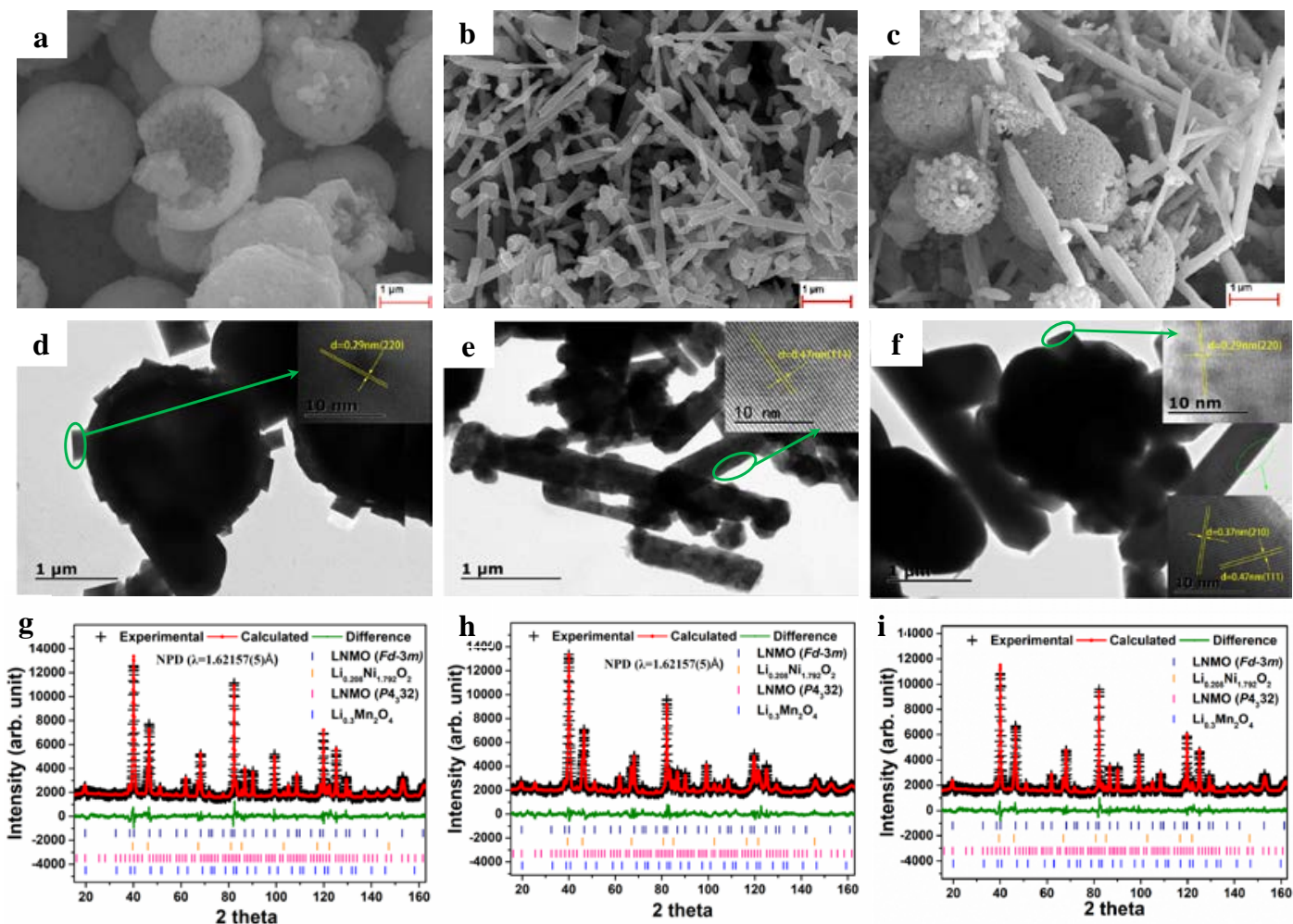

3 Fig. 1 SEM images of LNMO materials with different microstructures: a) spheres, b)

4 nanorods, c) the hybrid material; TEM images of LNMO materials with different

5 surface microstructures: d) spheres, e) nanorods, and f) the hybrid material. Insets of

6 the panels are HRTEM images of the corresponding selected area (marked by green

7 lines); Rietveld refinement profiles for the NPD data for (g) spheres, (h) nanorods, and

8 (i) the hybrid LNMO (weighted profile R-factor, $R_{\mathrm{wp}}=5.38$, 5.17, and $4.90 \%$;

9 goodness-of-fit $(\mathrm{GOF})=2.32,2.35$, and 2.01, respectively). 
(a)

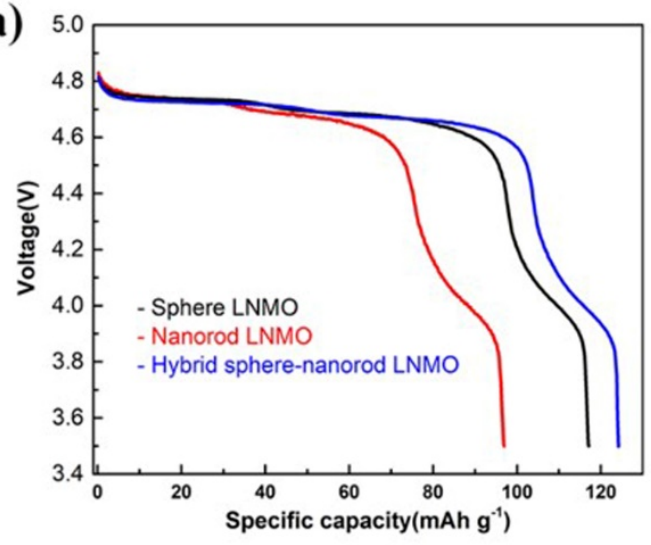

(c)

(e)

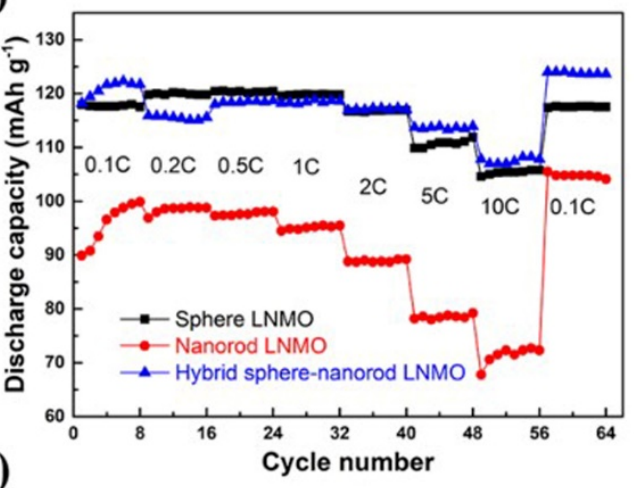

(b)

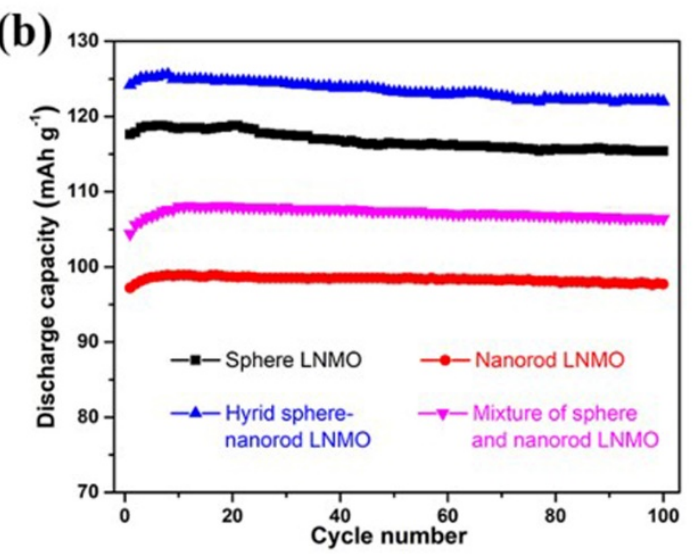

(d)

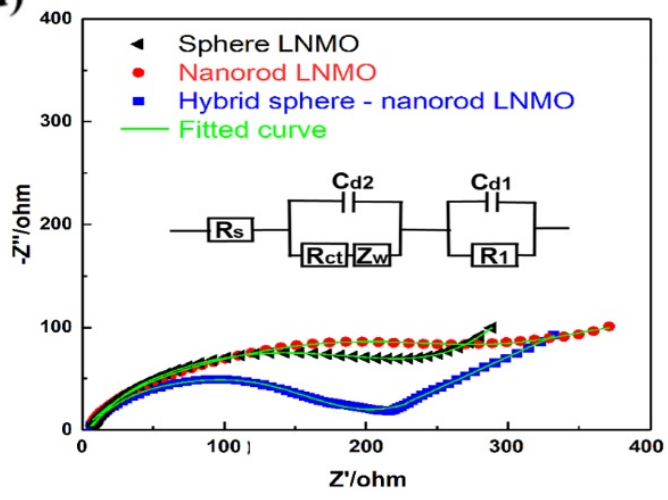

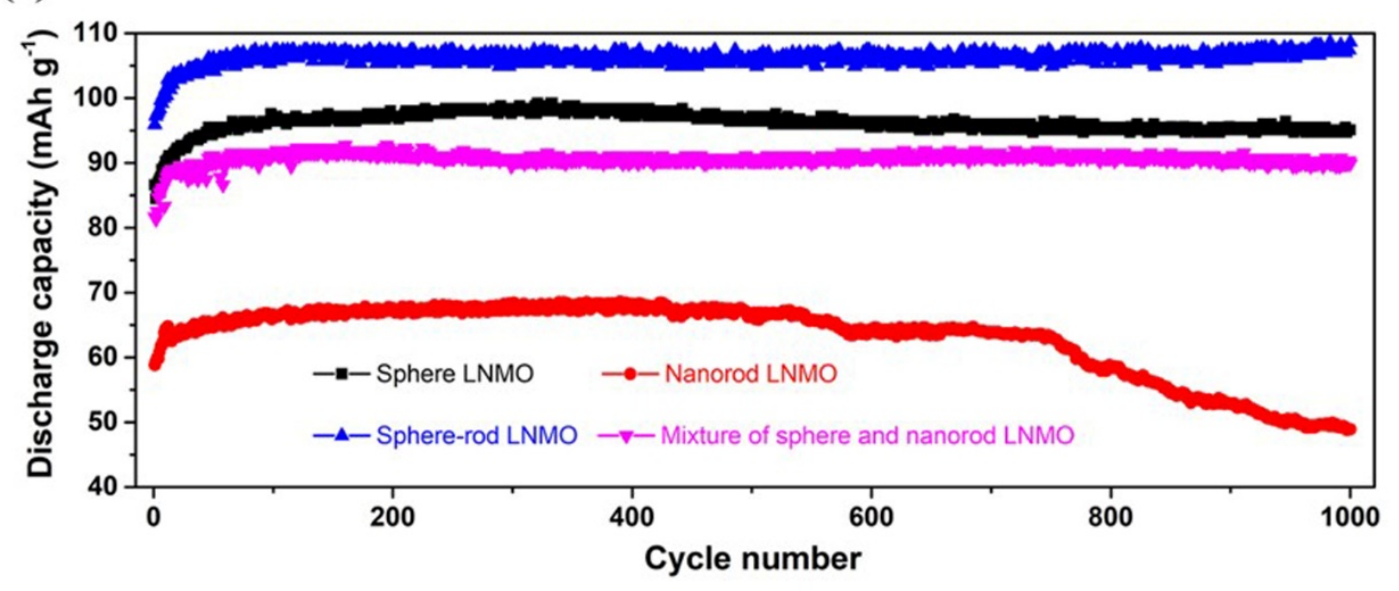

2 Fig. 2 Electrochemical behavior of the LNMO samples at room temperature. (a) Initial

3 discharge curves at $1 \mathrm{C}$, (b) cycling performance at $1 \mathrm{C}$, (c) rate capabilities at various

4 current densities, (d) Nyquist plots, with the inset showing the equivalent circuit used

5 to fit the EIS, and (e) long-term cycling performances of the four samples at $10 \mathrm{C}$. 

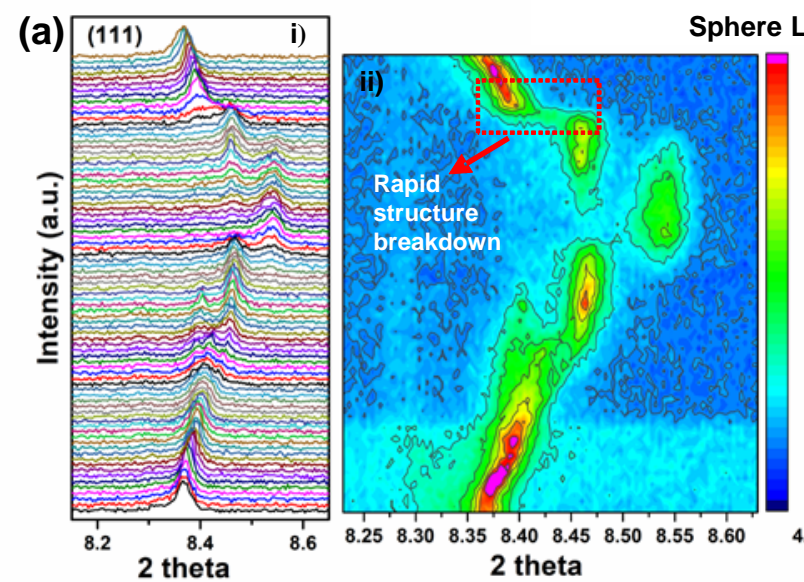

Sphere LNMO

(b)

2 theta
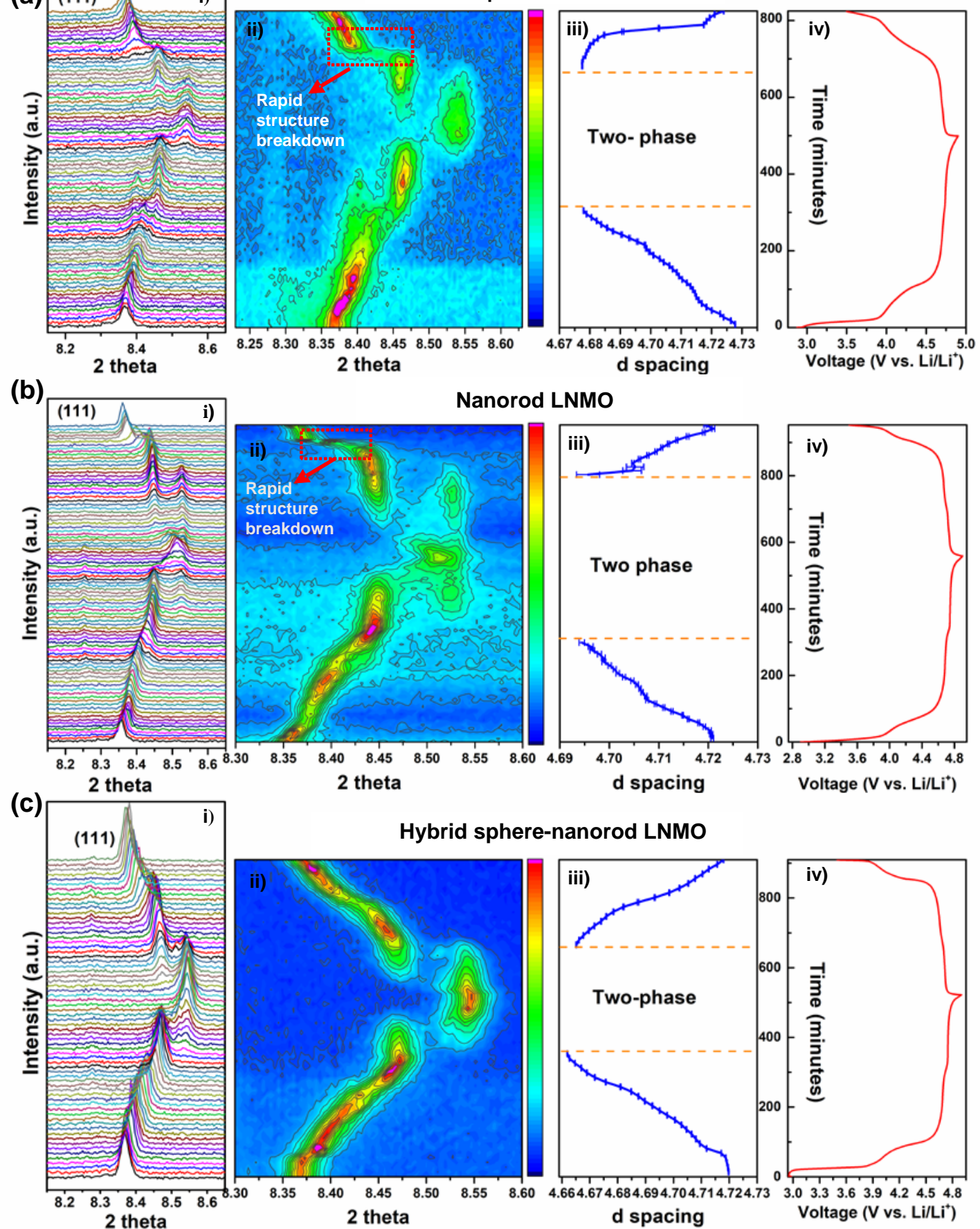

Hybrid sphere-nanorod LNMO
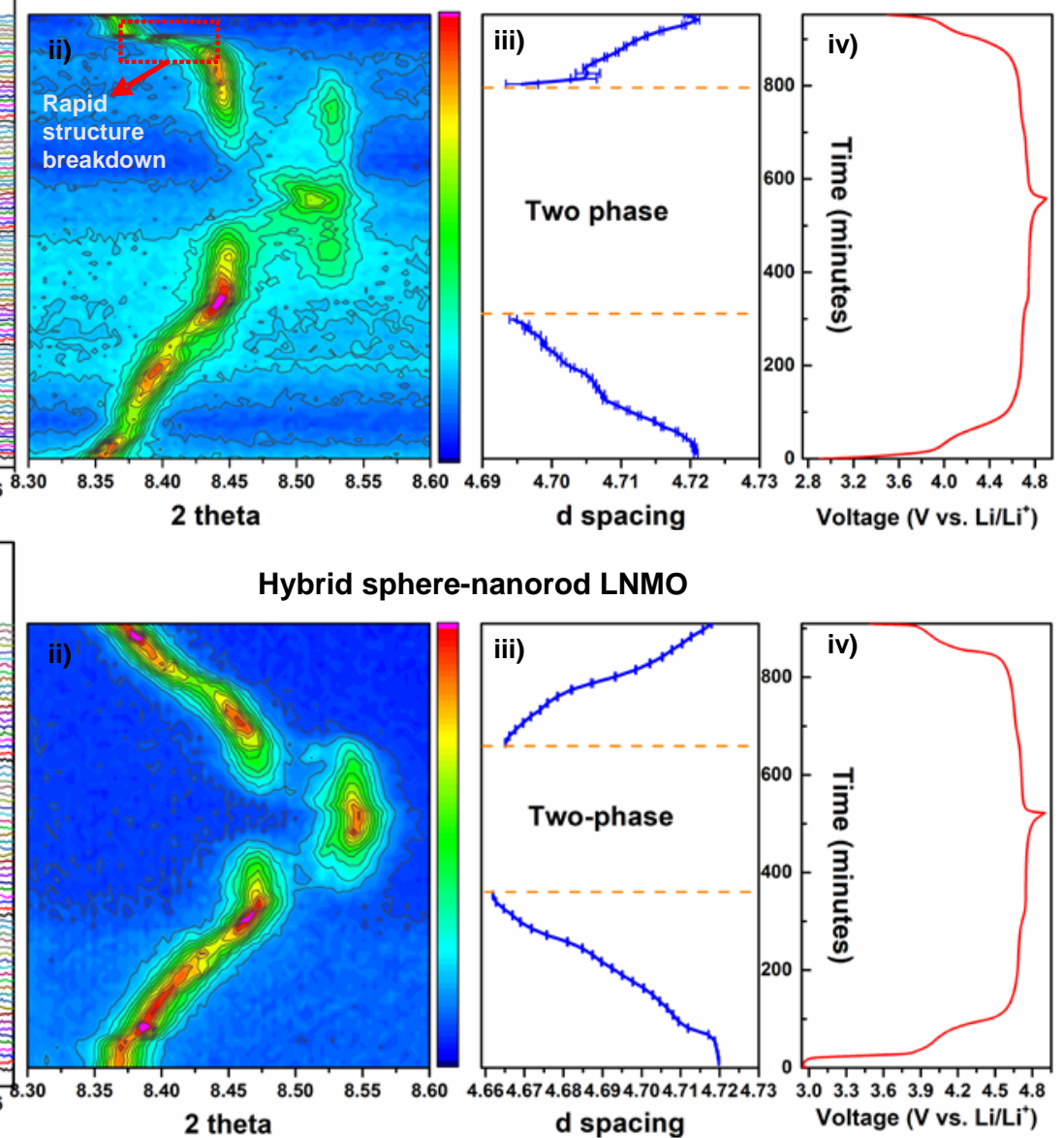

2 Fig. 3 In operando synchrotron-based XRD profiles of (a) sphere, (b) nanorod, and (c)

3 hybrid LNMOs with i) stacking and ii) contour plots of synchrotron XRD in the selected

4 2-theta region, showing the evolution of (111) reflections of LNMO, iii) variation of $d$

5 spacing of LNMO during charge and discharge, and iv) the corresponding charge-

6 discharge curves at $0.1 \mathrm{C}$.

7 


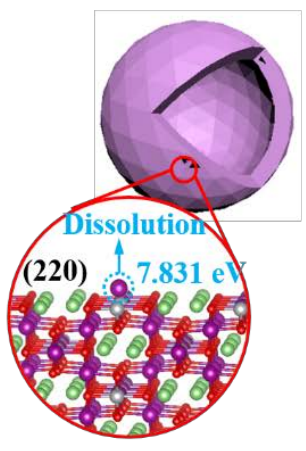

1

Mn-O coordination: 4

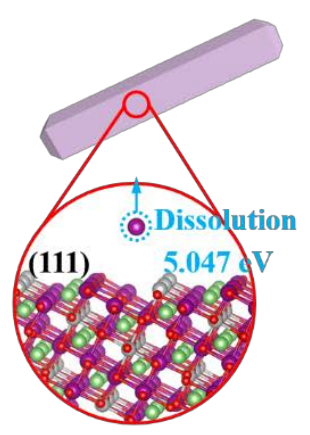

Mn-O coordination: 3

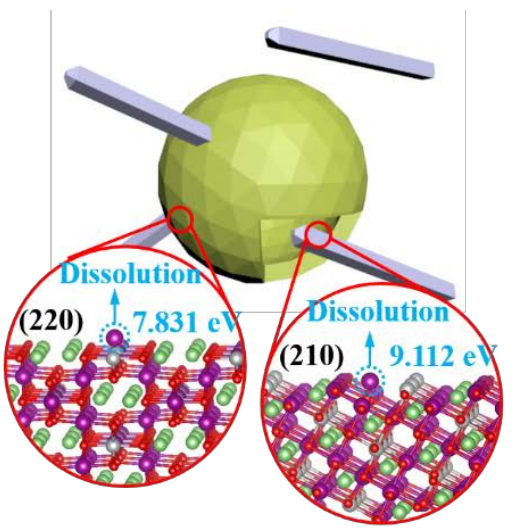

Mn-O coordination: 5

Mn-O coordination: $4 \& 5$

2 Fig. 4 Corresponding equivalent surfaces of (a) sphere, (b) nanorod, and (c) hybrid 3 LNMO samples, and the Mn ion dissolution from the corresponding surfaces (see Fig.

$4 \quad$ S7 and Table S5 for more details).

5 


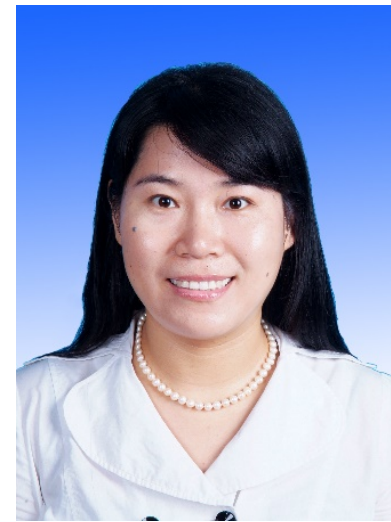

2 Dr. Haiping Liu received her $\mathrm{PhD}$ in chemical engineering and technology from 3 Harbin Institute of Technology in April 2008. Then, she joined Harbin Institute of 4 Technology (Weihai) as a faculty and became an associate professor of applied 5 chemistry in 2013. Her research interests include the design and application of electrode 6 materials energy for storage and conversion, including lithium ion/ sodium ion batteries 7 and lithium thermal batteries and surface finishing.

8

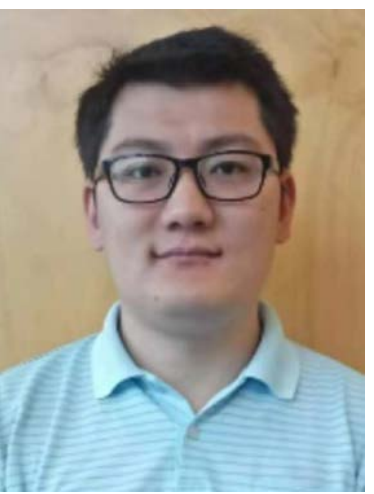

Gemeng Liang received his Bachelor's degree from Shandong University in 2014 and Master's degree from Tsinghua University in 2017. Currently he is a Ph.D. candidate at the Institute for Superconducting and Electronic Materials (ISEM), University of Wollongong, Australia, under the supervision of Dr. Wei Kong Pang, Prof. Vanessa Peterson and Prof. Zaiping Guo. His research focuses on the high-voltage cathode materials and their mechanistic behavior in lithium-ion batteries.

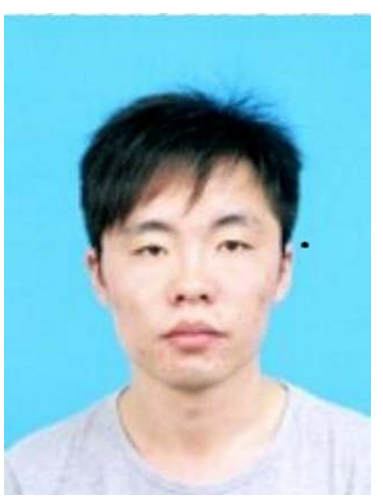

Chao Gao received his Bachelor's degree from Victory college of China University of Petroleum in 2014 and Master's degree from Northeastern University in 2017. 
1 Currently he is a Ph.D. candidate at chemical engineering and technology, Harbin 2 Institute of Technology, China, under Dr. Haiping Liu. His research focuses on the high3 voltage cathode materials and their behavior in lithium/sodium-ion batteries.

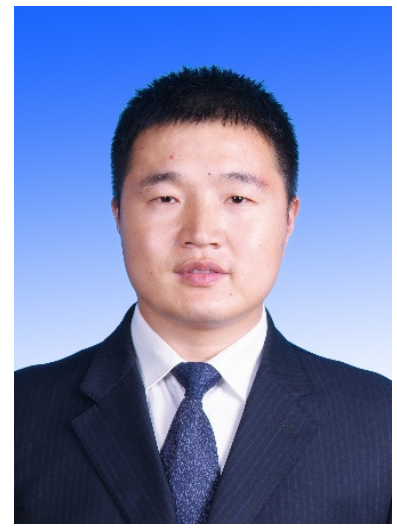

5 Sifu Bi received his Bachelor's degree in chemical engineering from Qilu University 6 of Technology in 1998 and Master's degree from Harbin Institute of Technology in 7 2007. Then, he joined Harbin Institute of Technology (Weihai) as a faculty and became 8 a senior engineer in 2013. His research interests include the design and application of 9 electrode materials for lithium ion/ sodium ion batteries and lithium thermal batteries and surface finishing.

11

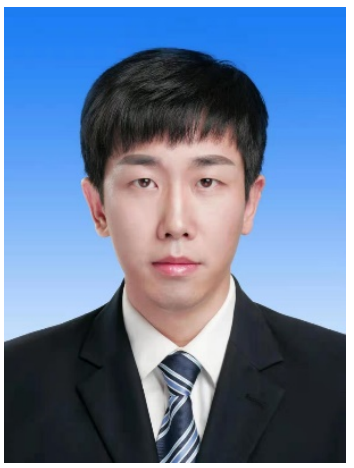

Qiang Chen received his Bachelor's degree in Chemical Engineering and Technology in 2016 and Master's degree from Harbin Institute of Technology in 2018. Currently he is an engineer in CATL, China. His research focuses on the high-voltage cathode materials and their behavior in lithium ion batteries.

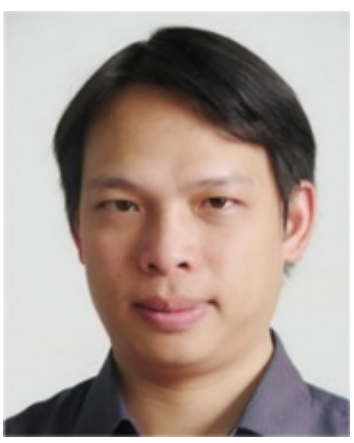

Dr. Ying Xie received his Ph.D degree in Chemical Engineering and Technology from Harbin Institute of Technology in 2008. He joined Heilongjiang University in 2008, and 
1 then became a member of Key Laboratory of Functional Inorganic Material Chemistry.

2 He currently is a professor of Heilongjiang University, China. His research interests

3 include theoretical predictions on the structures and properties of inorganic compounds

4 and the synthesis of electrode materials and their application in lithium-ion battery.

Shan-Shan Fan received her Bachelor's degree from Luoyang Normal University in 2015 and Master's degree from Heilongjiang University in 2018. Currently she is a Ph.D. candidate at chemical engineering and technology, Harbin Institute of Technology, China, under the supervision of Dr. Haiping Liu. Her research focuses on the synthesis and electrochemical performance of anode materials for lithium ion/sodium ion battery applications.

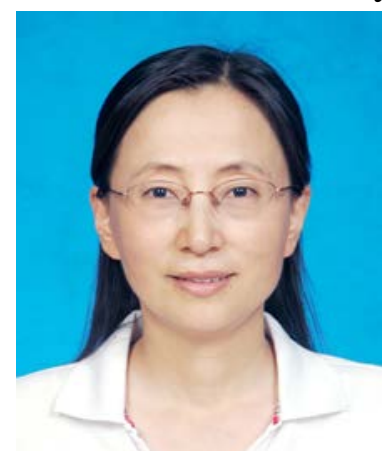

Dr. Lixin Cao joined Harbin Institute of Technology (Weihai) as a faculty in 1994 and became a professor of applied chemistry in 2009. She received her $\mathrm{PhD}$ in chemical engineering and technology from Harbin Institute of Technology in Oct. 2009. Her research interests include the design and application of electrode materials for lithium ion and lithium thermal batteries, electrochemical sensor and surface finishing.

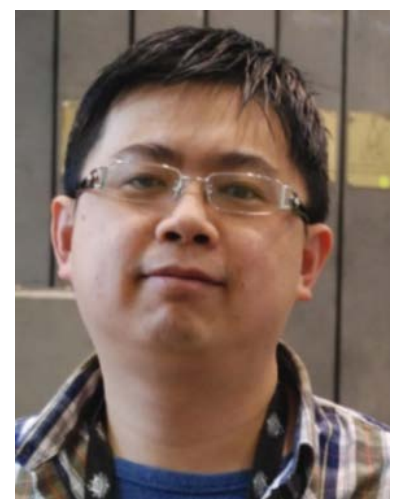

Dr. Wei Kong Pang received his Ph.D. in Applied Physics from Curtin University, Western Australia, in 2011. As a joint postdoctoral research fellow, he then focused on the research and development of Li-ion batteries at the National Taiwan University and 
1 the Department of Materials Engineering at Tatung University. Since June 2013, he has 2 been a joint postdoctoral fellow at University of Wollongong and Australian Nuclear 3 Science and Technology Organization. Currently he was awarded with an Australian 4 Future Fellowship and works as a senior research fellow at Institute for 5 Superconducting and Electronic Materials, University of Wollongong since 2016. His 6 main focus is the crystallography of materials for energy storage applications and 7 understanding their structure-function relationships. This includes understanding the 8 insertion/extraction mechanism and working principles of the electrode materials for 9 both Li- and Na-ion batteries by using a variety of in situ techniques.

10

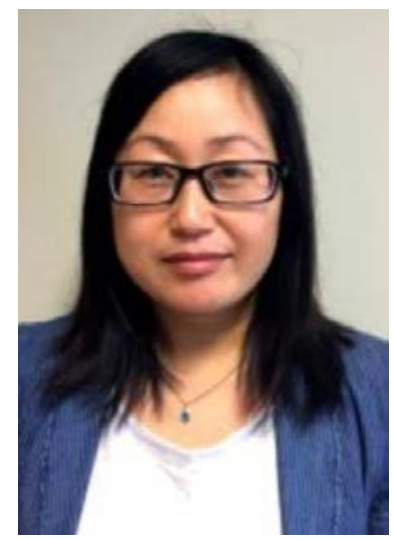

11 Prof. Zaiping Guo received her PhD in Materials Engineering from the University of 12 Wollongong in December 2003. After APD fellowship in the Institute for 13 Superconducting \& Electronic Materials, she joined Faculty of Engineering and 14 Information Sciences, University of Wollongong as a Lecturer in 2008, and was 15 promoted to Professor in 2012, and then Senior Professor in 2013. Her current research 16 interests focus on the design and application of nanomaterials for energy storage and 17 conversion, including rechargeable batteries, hydrogen storage, and fuel cells. 


\section{Supporting information for}

Insight into the improved cycling stability of sphere-nanorod-like micro-nanostructured high voltage spinel cathode for lithium-ion batteries

Haiping $\mathrm{Liu}^{\mathrm{a}, \mathrm{b}, 1, *}$, Gemeng Liang ${ }^{\mathrm{b}, 1}$, Chao $\mathrm{Gao}^{\mathrm{a}}$, Sifu Bi ${ }^{\mathrm{c}}$, Qiang Chen ${ }^{\mathrm{a}}$, Ying Xie ${ }^{\mathrm{d}, *}$, Shanshan Fan ${ }^{\mathrm{a}}$, Lixin $\mathrm{Cao}^{\mathrm{a}}$, Wei Kong Pang ${ }^{\mathrm{b}, *}$, Zaiping Guo ${ }^{\mathrm{b}, *}$

a School of Marine Science and Technology, Harbin Institute of Technology, Weihai 264209, PR

China.

b School of Mechanical, Materials, Mechatronic and Biomedical Engineering, Institute for Superconducting \& Electronic Materials, University of Wollongong, NSW 2522, Australia.

c School of Materials Science and Engineering, Harbin Institute of Technology, Weihai 264209, PR China.

${ }^{\mathbf{d}}$ Key Laboratory of Functional Inorganic Material Chemistry, Ministry of Education, School of Chemistry and Materials Science, Heilongjiang University, Harbin, 150080, PR China.

Ordered LNMO $\mathrm{P4}_{3} 32$

(a)

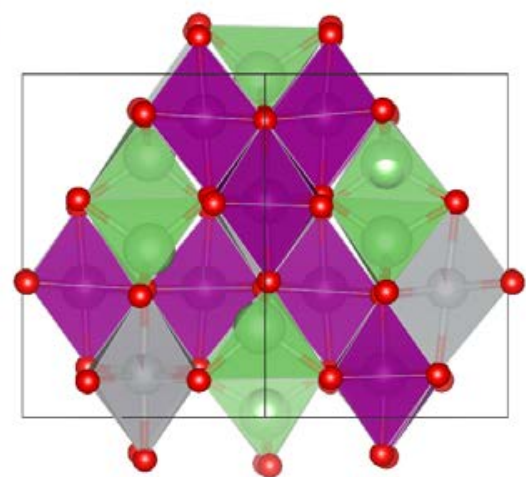

$\mathbf{L i}$ o

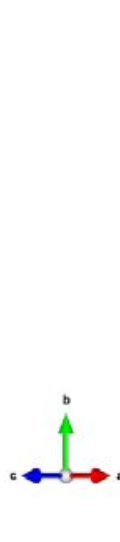

(b)

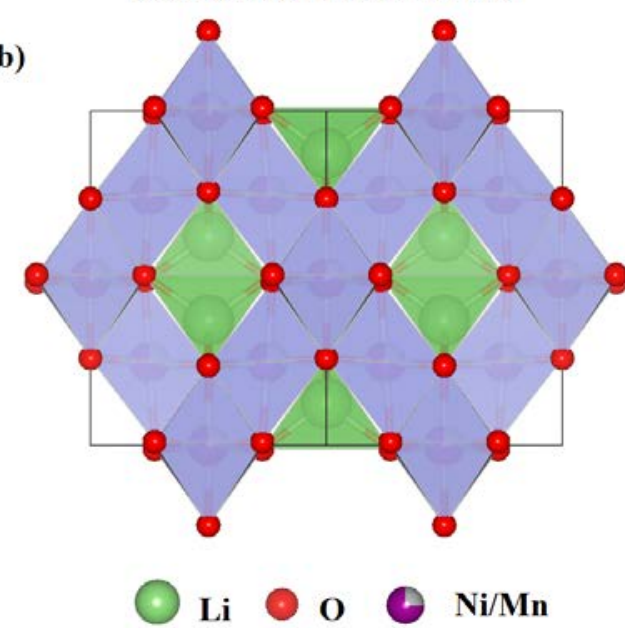

Fig. S1 Schematic structures of ordered LNMO $\left(\mathrm{P}_{3} 32\right)$ and disordered LNMO $(\mathrm{Fd}-3 \mathrm{~m})$

\footnotetext{
* Corresponding author at:

E-mail address: hpliuhit@126.com (H.-P. Liu), xieying@hlju.edu.cn (X. Ying), wkpang@uow.edu.au (W. K. Pang), zguo@uow.edu.au (Z. Guo)

${ }^{1}$ These authors contributed equally to this work.
} 


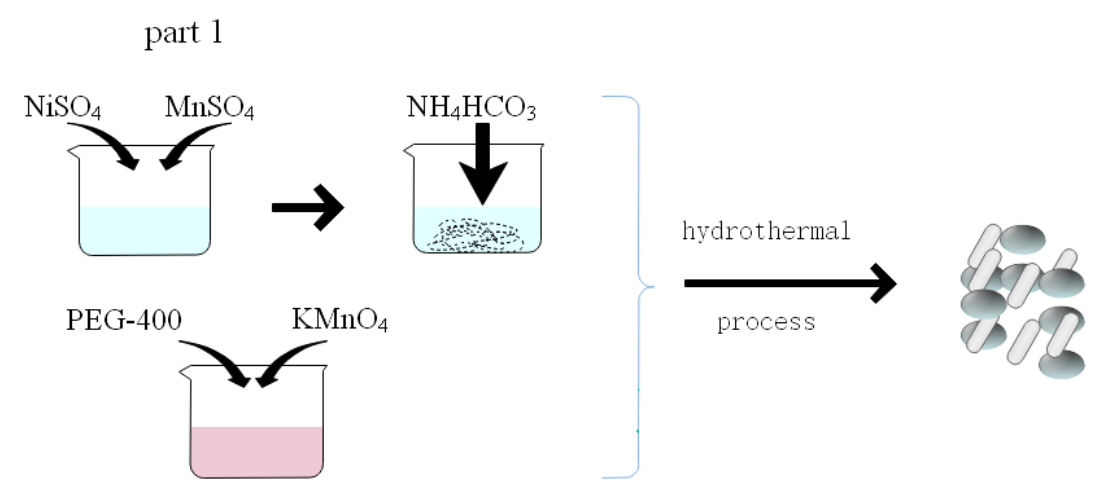

part 2

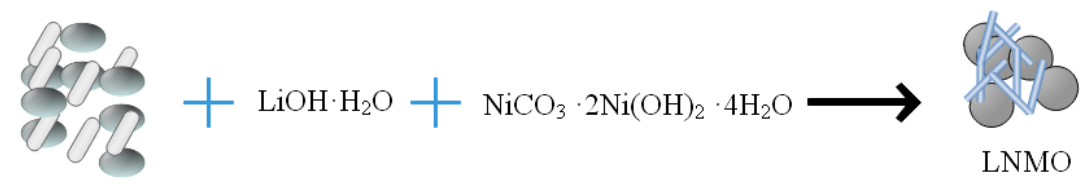

Fig. S2 Synthesis process of the sphere-rod-like micro-nanostructure LNMO materials.

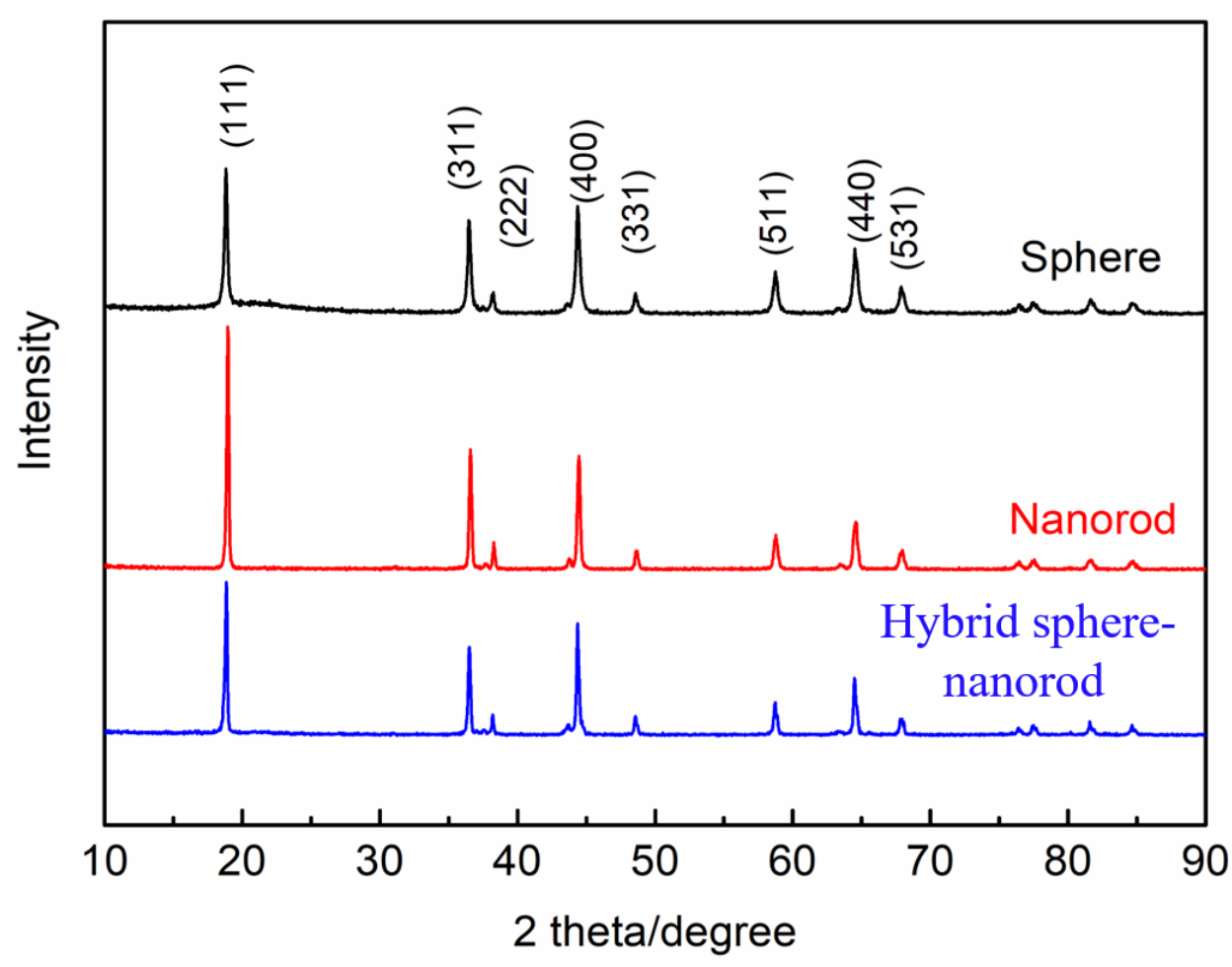

Fig. S3 XRD pattern of sphere, nanorod and hybrid sphere-nanorod LNMO, respectively 
Table S1 Phase fraction in three LNMO samples obtained from Rietveld refinements

\begin{tabular}{|c|c|c|c|c|}
\hline Weight fraction & $\mathrm{LNMO}(\mathrm{Fd}-3 \mathrm{~m})$ & $\mathrm{LNMO}\left(\mathrm{P4} 4_{3} 32\right)$ & $\mathrm{Li}_{0.208} \mathrm{Ni}_{1.792} \mathrm{O}_{2}$ & $\mathrm{Li}_{0.3} \mathrm{Mn}_{2} \mathrm{O}_{4}$ \\
\hline Sphere LNMO & $81.8 \mathrm{wt} \%$ & $2.7(2) \mathrm{wt} \%$ & $5.2(2) \mathrm{wt} \%$ & $4.3(2) \mathrm{wt} \%$ \\
\hline Nanorod LNMO & $77.6 \mathrm{wt} \%$ & $8.1(3) \mathrm{wt} \%$ & $6.6(1) \mathrm{wt} \%$ & $7.7(2) \mathrm{wt} \%$ \\
\hline $\begin{array}{c}\text { Hybrid sphere- } \\
\text { nanorod LNMO }\end{array}$ & $89.1 \mathrm{wt} \%$ & $2.5(2) \mathrm{wt} \%$ & $5.5(2) \mathrm{wt} \%$ & $2.9(1) \mathrm{wt} \%$ \\
\hline
\end{tabular}

Table S2 Crystallographic details in three LNMO samples

\begin{tabular}{|c|c|c|c|c|c|c|}
\hline \multicolumn{7}{|c|}{ Sphere LNMO Space group $=F d-3 m$} \\
\hline Atom & $\begin{array}{c}\text { Wyckoff } \\
\text { site }\end{array}$ & $x$ & $y$ & $z$ & $\mathrm{U}_{\text {iso }}\left(\AA^{2}\right)$ & $\begin{array}{c}\text { Site } \\
\text { occupancy } \\
\text { factor }\end{array}$ \\
\hline $\mathrm{Li}$ & $8 a$ & 0.125 & 0.125 & 0.125 & $0.015(2)$ & 1 \\
\hline $\mathrm{Ni}$ & $16 d$ & 0.5 & 0.5 & 0.5 & $0.010(2)$ & $0.195(3)$ \\
\hline $\mathrm{Mn}$ & $16 d$ & 0.5 & 0.5 & 0.5 & $0.010(2)$ & $0.805(3)$ \\
\hline $\mathrm{O}$ & $32 e$ & $0.26311(8)$ & $0.26311(8)$ & $0.26311(8)$ & $0.0100(4)$ & 1 \\
\hline
\end{tabular}

\begin{tabular}{|c|c|c|c|c|c|c|}
\hline \multicolumn{7}{|c|}{ Nanorod LNMO Space group $=F d-3 m$} \\
\hline \multicolumn{2}{|c|}{$a=8.1801(7) \AA$, volume $=547.3(1) \AA^{3}$} \\
\hline Atom & $\begin{array}{c}\text { Wyckoff } \\
\text { site }\end{array}$ & $x$ & $y$ & $z$ & $U_{\text {iso }}\left(\AA^{2}\right)$ & $\begin{array}{c}\text { Site } \\
\text { occupancy } \\
\text { factor }\end{array}$ \\
\hline $\mathrm{Li}$ & $8 a$ & 0.125 & 0.125 & 0.125 & $0.010(2)$ & 1 \\
\hline $\mathrm{Ni}$ & $16 d$ & 0.5 & 0.5 & 0.5 & $0.016(3)$ & $0.181(4)$ \\
\hline $\mathrm{Mn}$ & $16 d$ & 0.5 & 0.5 & 0.5 & $0.016(3)$ & $0.819(4)$ \\
\hline $\mathrm{O}$ & $32 e$ & $0.2627(1)$ & $0.2627(1)$ & $0.2627(1)$ & $0.0084(4)$ & 1 \\
\hline
\end{tabular}

\begin{tabular}{|c|c|c|c|c|c|c|}
\hline \multicolumn{7}{|c|}{ Hybrid sphere-nanorod LNMO Space group $=F d$-3m } \\
\hline Atom & $\begin{array}{c}\text { Wyckoff } \\
\text { site }\end{array}$ & $x$ & $y=8.1746(1) \AA$, volume $=546.27(3) \AA^{3}$ & $\mathrm{U}_{\text {iso }}\left(\AA^{2}\right)$ & $\begin{array}{c}\text { Site } \\
\text { occupancy } \\
\text { factor }\end{array}$ \\
\hline $\mathrm{Li}$ & $8 a$ & 0.125 & 0.125 & 0.125 & $0.012(1)$ & 1 \\
\hline $\mathrm{Ni}$ & $16 d$ & 0.5 & 0.5 & 0.5 & $0.006(2)$ & $0.202(3)$ \\
\hline $\mathrm{Mn}$ & $16 d$ & 0.5 & 0.5 & 0.5 & $0.006(2)$ & $0.798(3)$ \\
\hline $\mathrm{O}$ & $32 e$ & $0.26309(8)$ & $0.26309(8)$ & $0.26309(8)$ & $0.0096(2)$ & 1 \\
\hline
\end{tabular}

Table S3 Bond length obtained from Rietveld refinements in three samples

\begin{tabular}{|c|c|c|c|}
\hline Bond length $(\AA)$ & Sphere LNMO & Nanorod LNMO & $\begin{array}{c}\text { Hybrid sphere- } \\
\text { nanorod LNMO }\end{array}$ \\
\hline Li-O bond & $1.9545(4)$ & $1.9516(5)$ & $1.9552(4)$ \\
\hline Mn-O bond & $1.9414(7)$ & $1.9464(9)$ & $1.9426(6)$ \\
\hline
\end{tabular}




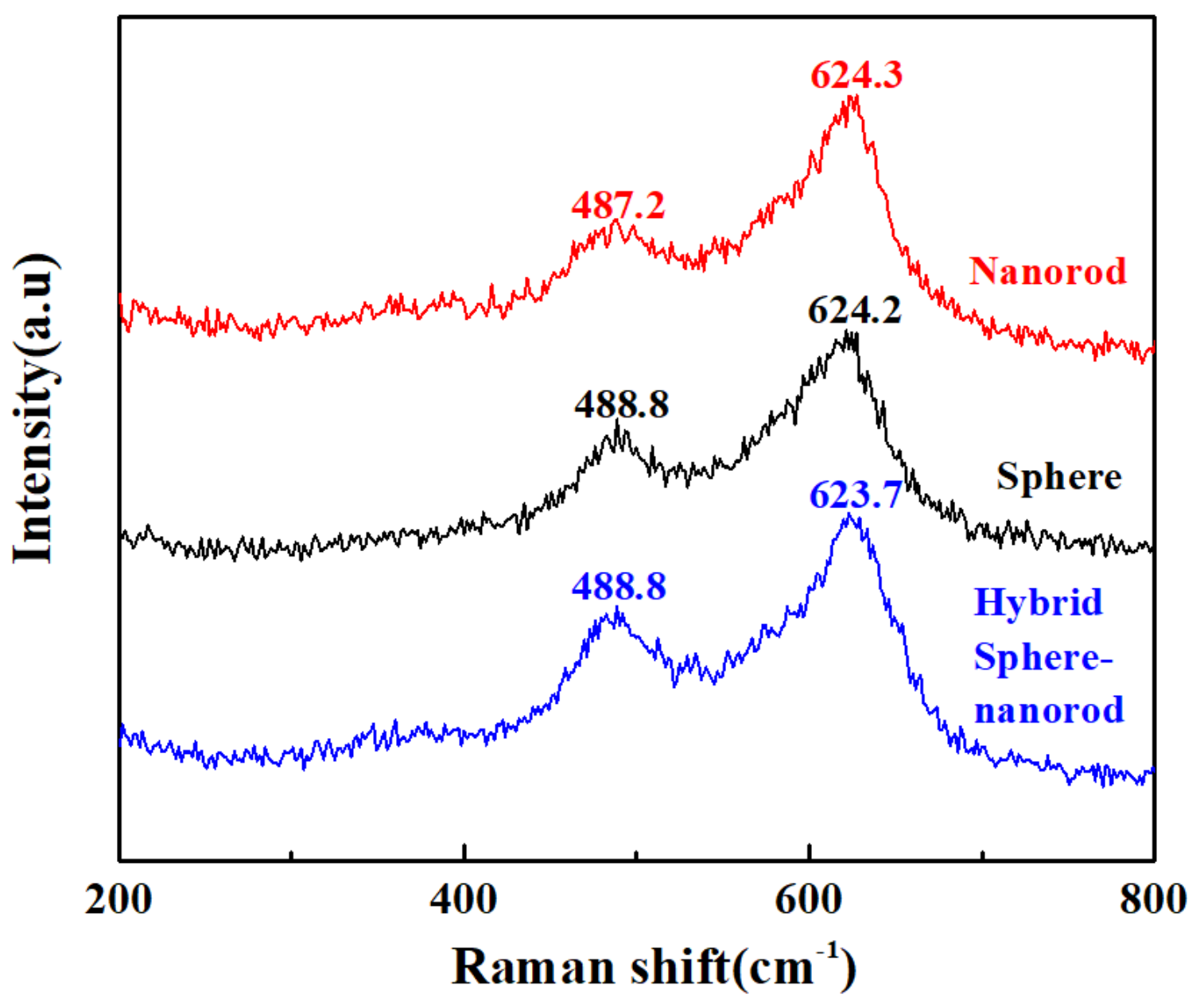

Fig. S4 Raman spectra of obtained LNMO materials with different microstructure. 


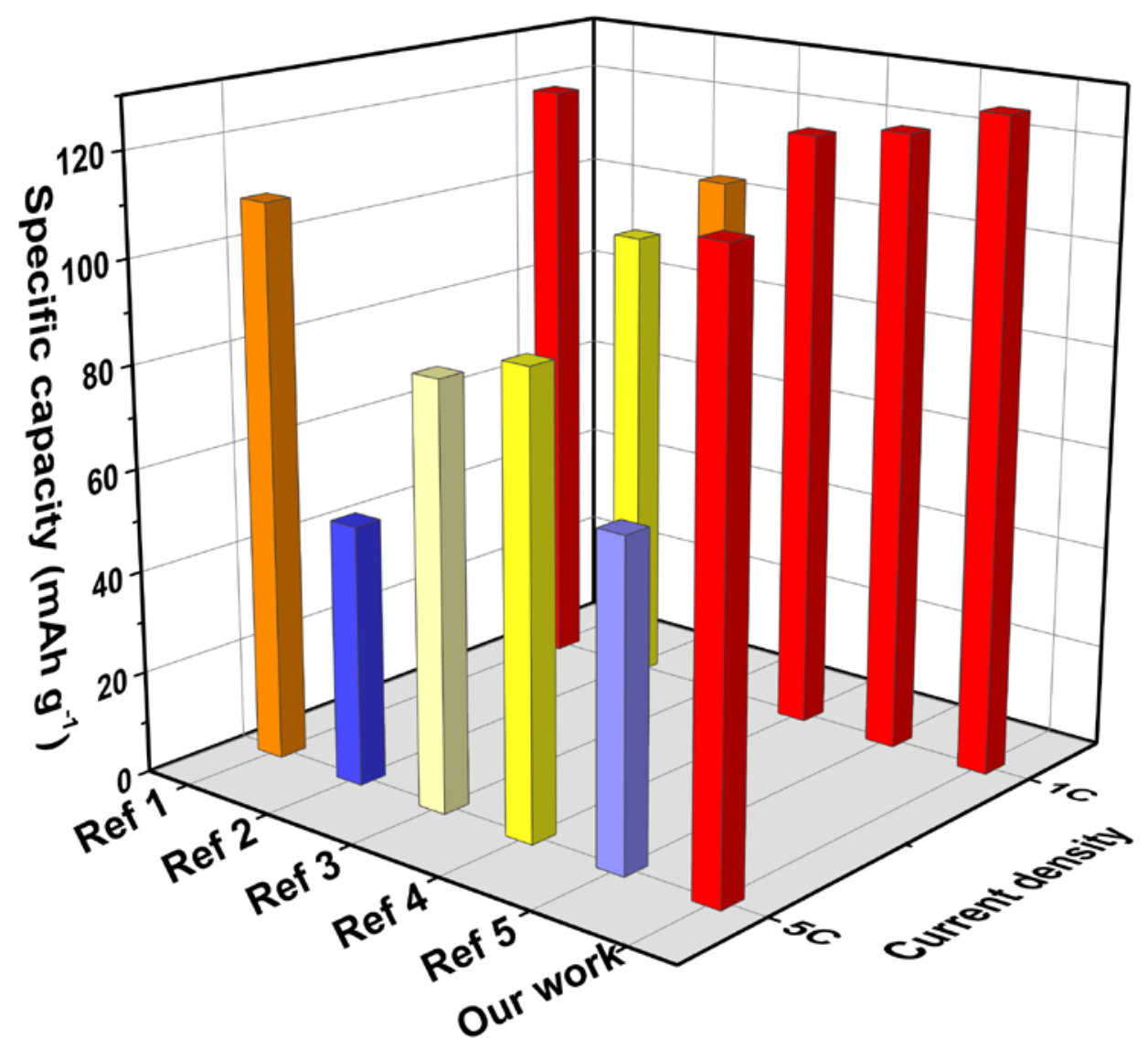

Fig. S5 rate capability comparison between our work and previous literatures ${ }^{1-5}$ at $1 \mathrm{C}$ and $5 \mathrm{C}$. 
(a)

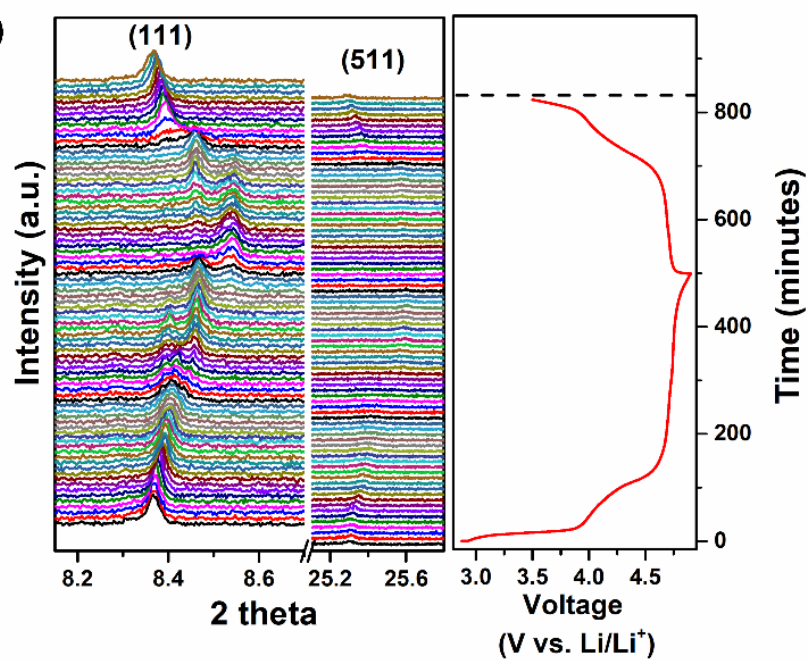

(b)

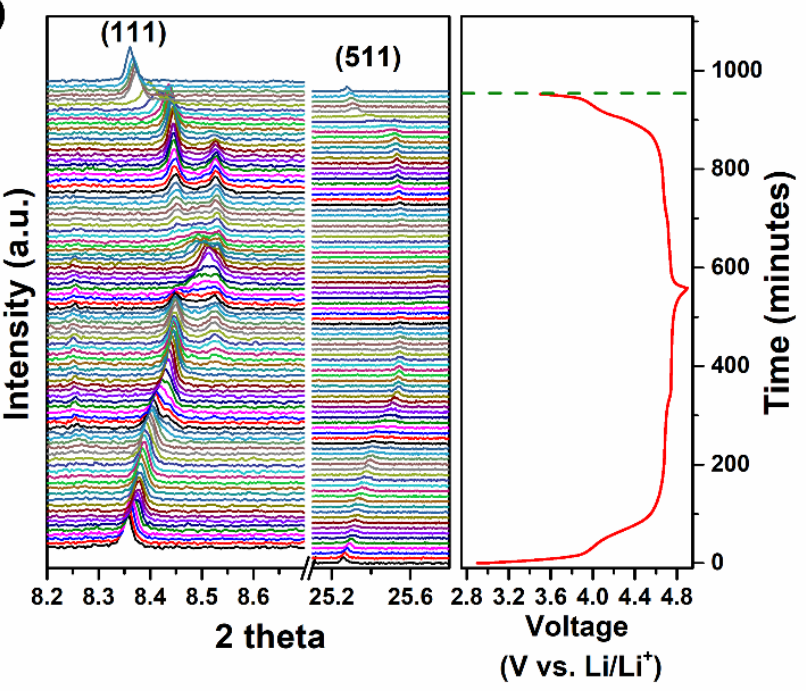

(c)

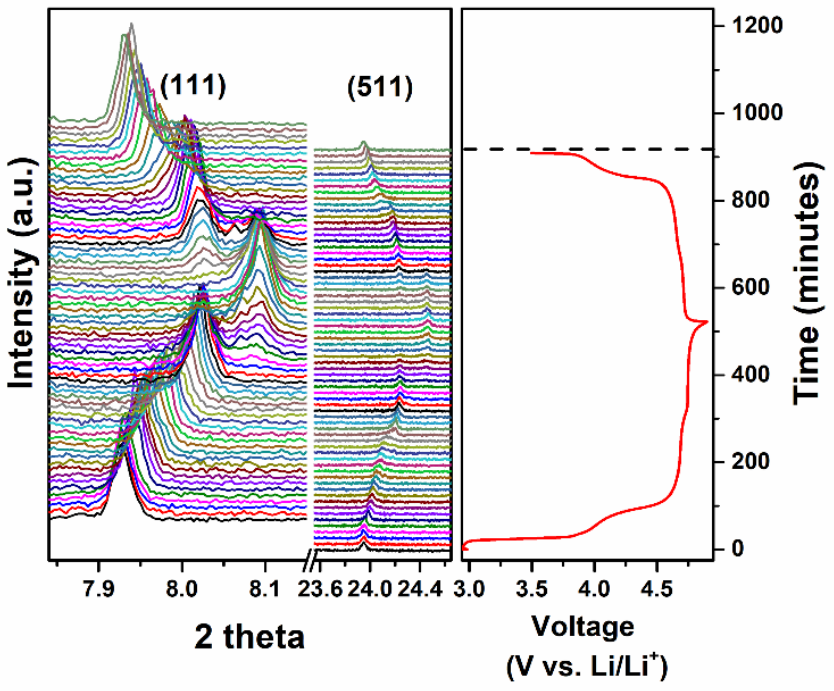

Fig. S6 Operando synchrotron XRD data of (a) sphere LNMO, (b) nanorod LNMO, and (c) hybrid sphere-nanorod LNMO. 
Table S4 the corresponding parameters of the hybrid sphere-nanorod-like LNMO material, single sphere LNMO and nanorod LNMO material.

\begin{tabular}{cccccc}
\hline Samples & $R_{S} / \Omega$ & $R_{c t} / \Omega$ & $R_{I} / \Omega$ & $C_{d 1} / 10^{-5} \mathrm{~F}$ & $C_{d 2} / 10^{-6} \mathrm{~F}$ \\
\hline $\begin{array}{c}\text { Hybrid sphere- } \\
\text { nanorod }\end{array}$ & 6.021 & 224.4 & 25.71 & 1.441 & 1.439 \\
Nanorod & 5.569 & 346.5 & 54.14 & 5.322 & 6.374 \\
Sphere & 5.422 & 235.5 & 34.65 & 2.245 & 6.155 \\
\hline
\end{tabular}

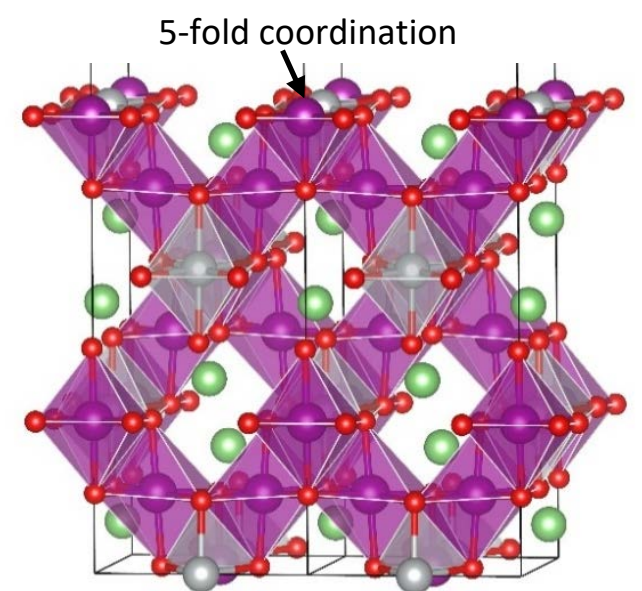

(a) (001) surface

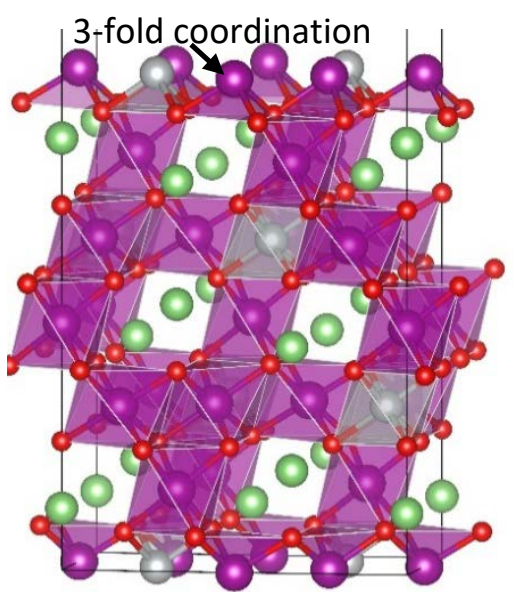

(c) (111) surface

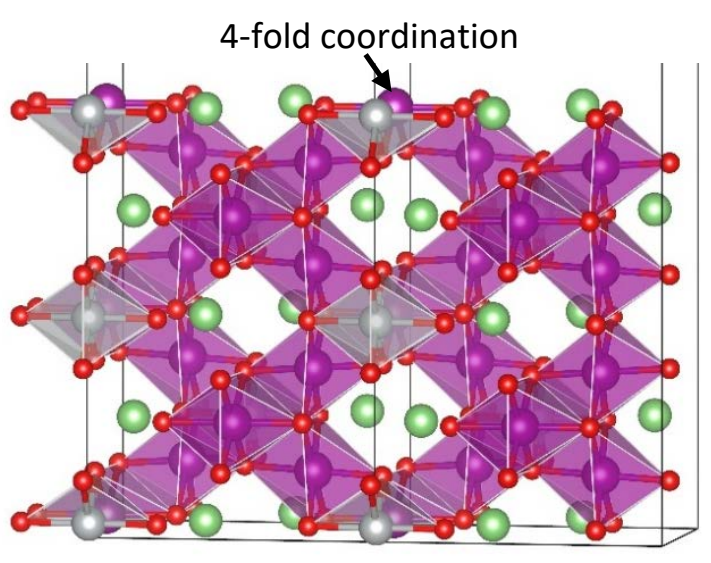

(b) (110) surface

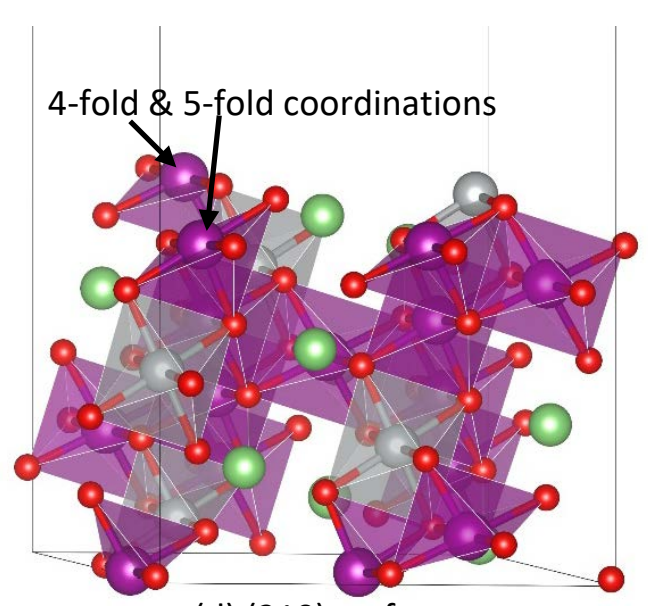

(d) (210) surface

Nickel

Manganess

Fig. S7 Theoretical models for (a) (001), (b) (110), (c) (111), and (d) (210) surfaces of $\mathrm{LiNi}_{0.5} \mathrm{Mn}_{1.5} \mathrm{O}_{4}$ material. 
Table S5 Formation energies (FE, in eV) of Mn defects on different surfaces and relevant Bader charges (BC, in $e)^{a}$.

\begin{tabular}{ccccc}
\hline & $(100)$ & $(110)$ & $(111)$ & $(210)$ \\
\hline FE & 10.627 & 7.831 & 5.0471 & 9.112 \\
BC & 1.513 & 1.390 & 0.994 & 1.440 \\
\hline \multicolumn{7}{c}{ Due to the symmetry, many surfaces are equivalent, i.e. (100), (100), and (010) ones. }
\end{tabular}
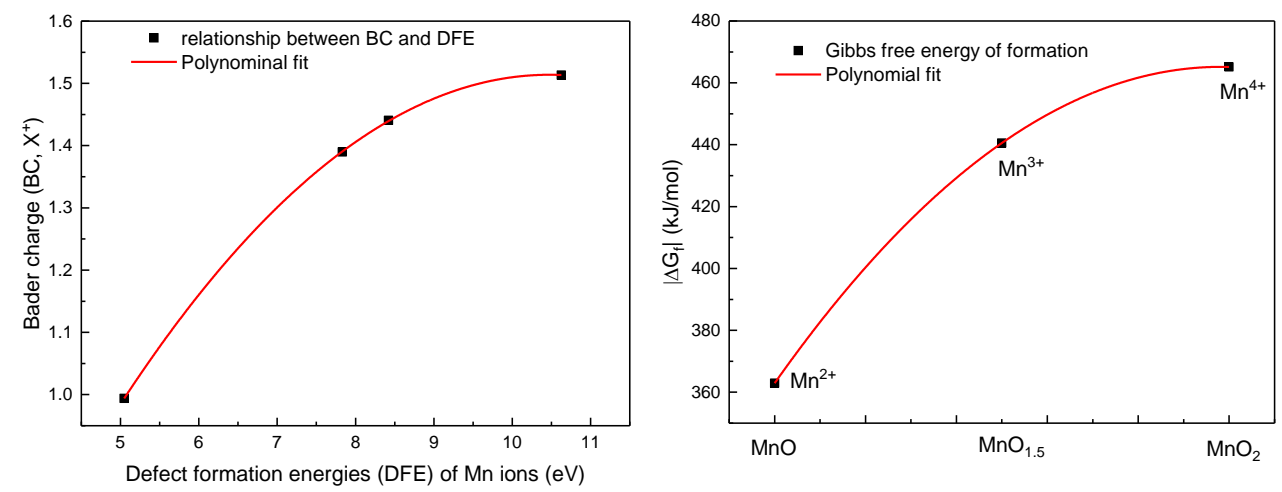

Figure S8 (a) Relationship between Bader charge and defect formation energy and (b) The Gibbs free energy of formation ( $\Delta \mathrm{Gf}$ ) for $\mathrm{MnOx}$ compounds

According to our calculated Bader charges and defect formation energies, a well-defined quadratic fit curve was obtained. A very similar trend was also observed in the relationship between the Gibbs free energy of formation ( $\Delta$ for $\mathrm{MnOx}$ compounds and the oxidation states of Mn ions). The data suggested that the stabilities of Mn ions in bulk and on surface are related to their oxidation states and the Mn-O coordination.

\section{Reference:}

1. Nageswaran, S.; Keppeler, M.; Kim, S.-J.; Srinivasan, M., Morphology controlled Si-modified $\mathrm{LiNi}_{0.5} \mathrm{Mn}_{1.5} \mathrm{O}_{4}$ microspheres as high performance high voltage cathode materials in lithium ion batteries. Journal of Power Sources 2017, 346, 89-96.

2. Deng, S.; Xiao, B.; Wang, B.; Li, X.; Kaliyappan, K.; Zhao, Y.; Lushington, A.; Li, R.; Sham, T.-K.; Wang, H.; Sun, X., New insight into atomic-scale engineering of electrode surface for long-life and safe high voltage lithium ion cathodes. Nano Energy 2017, 38, 19-27.

3. Xiao, B.; Liu, J.; Sun, Q.; Wang, B.; Banis, M. N.; Zhao, D.; Wang, Z.; Li, R.; Cui, X.; Sham, T. K.; Sun, X., Unravelling the role of electrochemically active $\mathrm{FePO}_{4}$ coating by atomic layer deposition for 
increased high-voltage stability of $\mathrm{LiNi}_{0.5} \mathrm{Mn}_{1.5} \mathrm{O}_{4}$ cathode material. Advanced Science 2015, 2 (5), 1500022.

4. Xiao, B.; Liu, H.; Liu, J.; Sun, Q.; Wang, B.; Kaliyappan, K.; Zhao, Y.; Banis, M. N.; Liu, Y.; Li, R.; Sham, T. K.; Botton, G. A.; Cai, M.; Sun, X., Nanoscale manipulation of spinel lithium nickel manganese oxide surface by multisite Ti occupation as high-performance cathode. Advanced Materials 2017, 29 (47).

5. Deng, Y.; Mou, J.; Wu, H.; Jiang, N.; Zheng, Q.; Lam, K. H.; Xu, C.; Lin, D., A superior $\mathrm{Li}_{2} \mathrm{SiO}_{3}-$ composited $\mathrm{LiNi}_{0.5} \mathrm{Mn}_{1.5} \mathrm{O}_{4}$ cathode for high-voltage and high-performance lithium-ion batteries. Electrochimica Acta 2017, 235, 19-31. 